\title{
Dynamic Investment and Financing under Personal Taxation*
}

\author{
Erwan Morellec ${ }^{\dagger} \quad$ Norman Schürhoff ${ }^{\ddagger}$
}

August 2008

\begin{abstract}
This paper examines the effects of capital gains taxation on firms' investment and financing decisions. We develop a real options model in which the timing of investment, the decision to default, and the firm's capital structure are endogenously and jointly determined. Our analysis demonstrates that the asymmetric taxation of capital gains and losses fosters investment by eroding the option value of waiting. It also shows that firms controlled by taxable investors employ more equity financing, the higher the firm's stock price and the worse the firm's historical performance. Using a large sample of U.S. industrial firms that are owned by taxable investors between 1970 and 2008, we present new evidence on corporate investment and financing policies, which is supportive of the model's predictions.
\end{abstract}

Keywords: real options; capital gains taxation; capital structure.

JEL Classification Numbers: G31, G32, H24, H32.

${ }^{*}$ We thank Pierre Collin-Dufresne, Julien Cujean, Darrell Duffie, Adlai Fisher, Richard Green, Dirk Hackbarth, Burton Hollifield, Chester Spatt, an anonymous referee, the editor (Matthew Spiegel), and audiences at a number of seminars and conferences for helpful comments. Financial support from the Swiss Finance Institute and from NCCR FINRISK of the Swiss National Science Foundation is also gratefully acknowledged.

${ }^{\dagger}$ Swiss Finance Institute, Ecole Polytechnique Fédérale de Lausanne (EPFL), and CEPR. E-mail: erwan.morellec@epfl.ch. Postal: Ecole Polytechnique Federale de Lausanne, College of Management, Odyssea 3.04, Station 5, Ch-1015 Lausanne, Switzerland.

${ }^{\ddagger}$ Swiss Finance Institute and University of Lausanne. E-mail: norman.schuerhoff@unil.ch. Postal: Ecole des HEC, University of Lausanne, Extranef 228, 1015 Lausanne, Switzerland. 


\section{Introduction}

Taxes are among the most palpable and pervasive distortions that corporations and investors face in practice. Since the Modigliani-Miller (1958) irrelevancy theorem, financial economists have purported a number of tax-based theories to explain the observed patterns in corporate investment and financing behavior. While there exists a rich literature that examines the effects of corporate and ordinary income taxes on capital budgeting, financial theory has made little headway in explaining the relation between capital gains taxes and firms' policy choices. ${ }^{1}$ Yet, since the asymmetric realization-based tax system allows investors to defer taxable capital gains and offset capital losses, an investor with low tax basis (low purchase price relative to current share price), Bill Gates say, faces a higher effective tax rate and has lower security valuations than the marginal investor.

A number of important questions naturally arise in such a context. First, how does personal taxation affect corporate investment and leverage choices? In particular, do firms controlled by shareholders with low tax basis, Microsoft say, pursue different capital budgeting policies than firms held largely by marginal investors? Second, should past loser stocks that have experienced tax-loss selling pressure pursue other investment and financing policies than winner firms? Finally, can tax policy constitute an effective mechanism to stimulate corporate investment?

Our purpose in this paper is to gain a better understanding of the effects of personal taxes on firms' investment and financing decisions by answering these and other related questions. To do so, we build a dynamic real-options model of the firm in which investors are subject to both ordinary income taxation and realization-based capital gains taxation (i.e., capital gains are taxed only when the investor sells the stock). This model yields an explicit characterization of the optimal investment and financing policies for a firm acting in the best interests of incumbent shareholders.

The analysis shows that capital gains taxes have two separate, first-order effects on firms' policy choices. First, by providing a hedge for poor corporate performance, capital

\footnotetext{
${ }^{1}$ Recent contributions (Hennessy and Whited, 2005, Hackbarth, Miao, and Morellec, 2006, Strebulaev, 2007) recognize that dynamic tax trade-offs have the potential to generate rich capital structure patterns, though crucial features of the tax treatment on capital gains are neglected in these models.
} 
loss offsets drastically erode the value of waiting to invest and restructure - the investment (timing) effect. Second, firms owned by taxable investors tilt their financing choices towards equity because of the equity tax shields provided by capital loss offsets - the financing effect. These effects generalize Miller's (1977) seminal irrelevancy theorem to asymmetric capital gain and loss taxation, and have so far not been studied. ${ }^{2}$

The investment timing effect follows from Bernanke's (1983) Bad-News Principle. A standard result in real options theory is that uncertainty and irreversibility give rise to an option value of waiting so that firms invest only once a project's rate of return exceeds the cost of capital by a potentially large option premium. The option value of waiting arises solely from the desire to avoid bad outcomes, i.e., unprofitable states. Capital loss offsets increase investors' after-tax payoffs in states where the firm's stock price performs poorly, presumably when operating performance is bad, while leaving payoffs in good states unaffected (where it is not optimal to sell shares). The asymmetric taxation of gains (good news) and losses (bad news) limits potential losses, diminishes the option value of waiting, and leads firms to impose a lower hurdle rate. One direct implication of this result is that firms owned by taxable investors with high basis overinvest relative to firms owned by low-basis investors.

The financing effect of capital gains taxation is the result of different security valuations across incumbent shareholders and new investors. Since capital gains remain untaxed until realized, each share entitles taxable investors to an tax timing option. The value of this tax timing (put) option increases with the tax basis (strike price) of the investor. As a result, incumbent investors have lower valuations than new investors whenever the market price exceeds the basis of incumbents (and the marginal investor is taxable). ${ }^{3}$ When this is the case, there exists a wedge between the private valuations of

\footnotetext{
${ }^{2}$ In Miller's clientele equilibrium, each leverage ratio is associated with a different clientele of investors and the value of any firm is independent of its capital structure. This result is fragile, however, as it requires that investors can trade shares without frictions. Realization-based taxation creates an incentive to defer gains, locks in incumbent investors, and alters their security valuations. Inevitably the clientele equilibrium breaks down in the presence of a lock-in effect, precluding investor unanimity. Schneller (1980), Constantinides (1983), and Hennessy and Whited (2005) also recognize that Miller's clientele equilibrium relies crucially on the ability to costlessly trade.

${ }^{3}$ The key prerequisite that the marginal investor is taxable is supported in the data. See the references
} 
locked-in incumbents and the market price. Newly issued shares entitle the investors to at-the-money options granted by the government, while incumbents' tax-loss selling options are out-of-the-money. The firm's current owners can extract this surplus by issuing equity and thereby diluting their ownership. The surplus is larger when the stock price is higher or when the owners' basis is lower. Firms controlled by taxable investors therefore issue more equity relative to debt the larger their stock price, and firms with low basis, infra-marginal shareholders are underlevered relative to firms with high-basis, marginal shareholders. This, in turn, implies that the target leverage ratio is path-dependent, nonstationary, and inversely related to past performance measures in a way that is consistent with the empirical evidence. ${ }^{4}$

To test the predictions of our model, we form a large sample of U.S. industrial firms that are owned by taxable investors. We restrict our attention to firms that performed an IPO between 1970 and 2008 and obtain a sample of more than 30,000 firm-year observations in 5,570 IPOs. Knowing the IPO date and price allows us to study the model's implications from a common starting point, to track the tax basis of investors with reasonable precision, and to make our findings comparable to the recent evidence on investment dynamics and the evolution of leverage. We first examine the implications of the model for corporate investment. Consistent with the model's predictions, we find that low basis firms invest less than high basis firms, controlling for stock prices and various firm characteristics known to affect investment. We then examine financing decisions and find that low basis firms raise more equity than high basis firms and shift their financing mix towards equity. Finally, we use a powerful difference-in-difference test to show that the same tax measures that predict policy choices for firms held by individuals do not predict investment and financing choices for firms held by institutions. The difference in sensitivity to the basis across tax sensitive and insensitive firms validates that our basis in Section 2.2 for details. Alternatively, capital gains taxes affect investment and financing decisions when management has decision rights over the firm's policy choices (see section 4.5).

${ }^{4}$ Baker and Wurgler (2002) show that the history of a firm plays a pivotal role in determining capital structure. Welch (2004) argues capital structure dynamics are dominated by corporate inertia. Other evidence suggests that capital structures slowly revert back to optimal leverage ratios (Leary and Roberts, 2005). Equity offerings have also been shown to be positively related to stock market performance (see Masulis and Korwar, 1986, Bayless and Chaplinsky, 1996, or Benninga, Helmantel, and Sarig, 2005). 
measures proxy for personal tax effects. Overall, the patterns we find in the investment and financing decisions of our sample firms are supportive of the model's predictions.

The link between taxes and capital budgeting has been studied extensively, yet exclusively in different contexts. Gordon (1985) shows that taxes do not distort investment if the reduction in expected returns is compensated by a reduction in systematic risk. This neutrality result breaks down under an asymmetric tax system with limited offset provisions for tax losses or with realization-based capital gains taxes. Green and Talmor (1985) find that imperfect corporate tax loss offsets lead to underinvestment. This effect arises because of the convexity in the tax liability, which induces pseudo risk-averse behavior and discourages investment. Conversely, we show that the lock-in effect of realization-based capital gains taxation generates a concavity in after-tax payoffs that fosters pseudo riskloving corporate behavior. Finally, Hennessy and Whited (2005), Sundaresan and Wang (2006), and Lobanov and Strebulaev (2007) study the magnitudes of dynamic investment and financing distortions due to conflicts of interest between debt- and equityholders, while this paper focuses on conflicts amongst equityholders with different tax status.

The remainder of the paper is organized as follows. Section 2 lays out the model. Section 3 solves the model. Section 4 examines the effects of personal taxation on default risk, corporate investment, and capital structure. Section 5 tests the model's predictions. Section 6 concludes. Technical developments are gathered in the Appendix.

\section{The Model}

\subsection{Assumptions}

Throughout the paper, agents are risk neutral and discount cash flows at a constant aftertax interest rate $r$. We consider a firm with assets in place that generate a continuous flow of pre-tax operating income $\pi X_{t}$, where $\pi \in[0,1]$ is a constant scaling factor and $X=\left(X_{t}\right)_{t \geq 0}$ is a cash flow shock governed by the process

$$
d X_{t}=\mu X_{t} d t+\sigma X_{t} d W_{t}, \quad X_{0}>0
$$

In this equation, $\mu<r$ and $\sigma>0$ are constant parameters and $W=\left(W_{t}\right)_{t \geq 0}$ is a standard Brownian motion. In addition to its assets in place, the firm owns a growth option to 
increase capacity and operating income from $\pi X$ to $X$. The cost of investment is constant and denoted by $I$. The parameter $\pi$ determines the growth potential of the firm. The two extreme values for $\pi$ illustrate the nature of the real option. When $\pi=0$, the firm owns an investment project and has no assets in place. When $\pi=1$, the firm has no growth potential but can reorganize its capital structure at a cost $I$.

The firm goes public at date $t=0$. After the initial round of financing, the firm's capital structure consists of $n^{0}=1$ share of common equity and perpetual non-callable debt with coupon flow $c^{0}$. To fund the investment project, the firm sells new securities an optimal mix of debt and equity. We denote by $n^{1}$ the number of shares outstanding after the second round of financing and by $c^{1}$ the aggregate debt coupon. We assume that the old and new debt have equal seniority. The tax basis of a given share, i.e., the price at which it was acquired, is denoted by $B$. The decision to default is endogenous and chosen by shareholders. ${ }^{5}$ Bankruptcy costs consume a fraction $\alpha \in(0,1]$ of the firm's capital stock, as in Leland (1994).

Financial markets are frictionless and competitive, and collateralized short-sales are feasible (section 4.6 examines the effects of transaction costs). The tax code provisions and the assumptions on the financial markets are borrowed from Constantinides (1983). Specifically, capital gains are taxed upon realization at the statutory rate $\tau \geq 0$. Investors are rational, taxable, and have full use of capital loss offsets. ${ }^{6}$ The provisions for ordinary income taxation are standard. The personal tax rates on interest and dividend income are denoted by $\tau^{p}$ and $\tau^{d}$, respectively. The firm is subject to corporate income taxation at the rate $\tau^{c}$ and distributes its net income as dividends since the double-taxation imposes a prohibitive cost on internal funds. ${ }^{7}$ The effective tax rate on ordinary equity income is $\tau^{e}=1-\left(1-\tau^{c}\right)\left(1-\tau^{d}\right)$. Coupon payments are tax-deductible with full loss offsets.

\footnotetext{
${ }^{5}$ Intermediate funding shortfalls are met through rights issues to existing equityholders, where management has leeway in setting the subscription price to keep the aggregate tax basis unaffected. In effect this resembles the deep pocket assumption in Fischer, Heinkel and Zechner (1989) and Leland (1998).

${ }^{6}$ Current IRS rules allow capital losses to cancel out capital gains in the calculation of taxable gains, if an individual or corporation realizes both gains and losses in the same year. For individuals, if losses exceed gains in a year, the losses can be claimed as a tax deduction against ordinary income, up to $\$ 3,000$ per year. Additional net capital loss can be carried forward to the next year and netted out against future gains. Corporations can carry back capital losses to offset capital gains from prior years.

${ }^{7}$ For tractability the choice between dividends and share repurchases is not analyzed. While Green
} 


\subsection{Capital gains taxes and the lock-in effect}

As shown by Constantinides (1983), realization-based capital gains taxation creates a lock-in effect for taxable investors that breaks the irrelevancy and unanimity theorems of Modigliani and Miller (1958) and Miller (1977). Notably, incumbent investors are reluctant to sell shares with embedded gains and we have the following result (all proofs are relegated to the Appendix).

Proposition 1 Investors' optimal trading strategy is to defer capital gains and immediately realize capital losses until the firm defaults on its debt obligations. The default decision is supported unanimously by equityholders, since all shareholders have rationally reset their tax basis to zero by the time of default.

The first part of Proposition 1 follows from the fact that capital gains remain untaxed until the shares are sold. While trading frictions may hamper this strategy in practice, there is plenty of empirical evidence for tax-induced trading and for the lock-in effect influencing stock market valuations (see e.g. Grinblatt and Keloharju, 2000, Ivković, Poterba, and Weisbenner, 2005, and Jin, 2006) - lending support to the model. The intuition for the second part of the Proposition is as follows. The share price falls as operating performance deteriorates and default approaches. By selling their shares at a price $p$ prior to default, equityholders get the after-tax proceeds $p-\tau(p-B)$. By contrast, if they do not engage in tax loss selling, shareholders are left only with a tax credit $\tau B$ at the time of default. Since $p \geq 0$, shareholders optimally realize losses and reset their basis values as equity value decreases. Because all shareholders have reset their tax basis to zero by the time of default, the decision to default is unanimously supported.

and Hollifield (2003) show that repurchases can be more attractive than dividends on a tax basis, the Internal Revenue Code prohibits firms from disguising dividends in the form of share repurchases (note also that Feldstein and Summers (1979) show that the failure to index basis for inflation can create capital gains tax rate over 100\%). The Internal Revenue Code, Sec. 302. "Distributions in redemption of stock," stipulates that "if a corporation redeems its stock," such a "redemption shall be treated as a distribution" if the redemption is "essentially equivalent to a dividend." Proportionate repurchases, in particular, are treated the same as dividends for tax purposes. In our model, share repurchases to distribute the firm's net income would clearly be proportionate repurchases. 
We show below that while locked-in investors agree on the default decision, they generally disagree about investment and financing. When determining the firm's policy choices, we consider that managers act in the interests of the incumbent shareholders, that is they maximize private valuations. ${ }^{8}$ When maximizing shareholder wealth, managers recognize that the firm's pool of shareholders changes through time as the stock price evolves and stockholders reset their basis by selling their shares. In particular, each stock price path is associated with a different set of shareholders and a different tax basis for incumbents (and, hence, with different policy choices). It is important to stress that management's objective is well-defined and time-consistent. The collateral requirements introduced above preclude tax-arbitrage (as in Constantinides, 1983). In addition, new investors are not being expropriated since they rationally anticipate the firm's decisions and pay a fair price for the securities they invest in. Key for the results that follow is the fact that the decision maker is locked-in and thus infra-marginal for pricing.

\subsection{Private valuations vs. market prices}

The current realization-based tax system implies that capital gains remain untaxed until realized. As a result, each share entitles investors to a tax timing (put) option with strike price equal to the tax basis of the investor. The higher is this tax basis, the larger is the value of the option to realize tax losses. Private valuations therefore differ across investors, even though all investors receive the same cash distributions. In addition, this lock-in effect drives a wedge between the private valuations of incumbents and the market price set by new investors.

To understand the relation between private valuations and market prices and its implications for capital budgeting, denote by $T_{u}$ the time of the real option exercise and

\footnotetext{
${ }^{8}$ Alternatively, one can think of the manager's tax basis as the relevant one. This is the case for example when the manager has decision rights over the firm's policy choices and is constrained to hold some stock in the firm. Such liquidity restrictions can be imposed on executives for legal reasons (SEC Rule 144). They can also be imposed by contract. Kole (1997) documents that the minimum holding period before any shares can be sold ranges from 31 to 74 months in her sample. For more than a quarter of the plans the stock cannot be sold before retirement. We investigate this case in Section 4.5.
} 
by $M=\left(M_{t}\right)_{t \geq 0}$ the stopped minimum process associated with $X$ :

$$
M_{t}=\inf _{0 \leq s \leq \min \left(t, T_{u}\right)} X_{s}
$$

At any date $t \leq T_{u}, M_{t}$ coincides with the worst historical performance for the firm and, hence, with the threshold at which incumbents' should sell their shares. Indeed, as shown in Proposition 1, the optimal trading strategy for taxable investors is to defer gains and immediately realize losses. As a result, selling is optimal whenever the stock price falls to a new low. Since the stock price is monotonic in earnings, historical stock price lows map one-to-one into the running minimum $M_{t}$ of pre-tax earnings $X_{t}$.

Let $(x, m)$ denote realizations of $(X, M)$ in $\mathcal{S}=\left\{(x, m) \in \mathbb{R}^{+} \times \mathbb{R}^{+}: x \geq m\right\}$ and define

$$
\begin{array}{ll}
v^{i}(x, m ; B): & \text { Private valuation of a share with tax basis } B, \\
p^{i}(x, m): & \text { Stock price, } \\
D^{i}(x, m): & \text { Market value of the aggregate debt outstanding, } \\
i=0,1: & \text { Time period before }(0) \text { or after }(1) \text { investment. }
\end{array}
$$

In addition, denote by $b^{i}(m ; B)$ the threshold for pre-tax income that triggers the sale of a share purchased at basis $B$. According to Proposition 1, the optimal strategy for investors is to keep the basis-price ratio from exceeding unity: $B \leq p^{i}(x, m)$. As a result, the tax-loss selling threshold $b^{i}(m ; B)$ satisfies

$$
p^{i}\left(b^{i}(m ; B), m\right)=B .
$$

The relation between private valuations and market prices can then be derived as follows. The competitive clearing condition requires that the market price of any financial claim is set by new investors (Williams, 1985). Since investors enter with a tax basis equal to the market price, the market price compounds an at-the-money tax timing option. This creates the following fixed-point problem linking private valuations to market prices:

$$
p^{i}(x, m)=v^{i}\left(x, m ; p^{i}(x, m)\right), i=0,1,(x, m) \in \mathcal{S} .
$$

Since private valuations increase with the tax basis of investors, it follows from equations (3) and (4) that the private valuation of every incumbent is lower than the market price, i.e., $v^{i}(x, m ; B) \leqq p^{i}(x, m)$, for all $x \geqq b^{i}(m ; B)$. Finally, the valuation of the managerial decision maker satisfies $v^{i}(x, m) \equiv v^{i}\left(x, m ; p^{i}(m, m)\right), i=0,1$. 


\section{The Firm's Capital Budgeting Problem}

In our model, management makes three types of decisions. First, it selects the firm's investment policy, i.e., the investment boundary $u(m)$. Second, it selects the firm's default policy, i.e., the default thresholds before and after investment $l^{0}(m)$ and $l^{1}(m)$. Third, it selects the firm's financing policy, i.e., the coupon payment and the number of shares outstanding after the second round of financing $c^{1}(m)$ and $n^{1}(m)$.

When making these policy choices, management acts in the best interests of incumbent shareholders (see however Section 4.5) and takes into account the dynamics of their tax basis. As a result, a time-independent trigger strategy is not optimal. Rather, since the tax basis of shareholders is captured by the running minimum $M$ of the cash flow shock $X$, the value-maximizing policy choices depend on both the firm's current performance, i.e., $X_{t}=x$, and the firm's historical performance, i.e., $M_{t}=m$. Importantly, and as noted above, managers recognize that the firm's pool of shareholders changes through time as the stock price evolves so that the relevant tax basis for corporate decisions is captured by $m$. In particular, in our setup the identity of shareholders does not matter. Whenever the price hits a new low, current investors sell out to a new set of investors who pick up the new basis so that management only needs to know the firm's historical performance to keep track of the basis of incumbents.

Formally, management's optimization problem can be written as

$$
\sup _{u(m), c^{1}(m), n^{1}(m), l^{0}(m), l^{1}(m)} v^{0}(x, m)
$$

subject to the budget constraint

$$
p^{1}(u(m), m)\left[n^{1}(m)-1\right]+D^{1}(u(m), m)-D^{0}(u(m), m)=I,
$$

where $\left(c^{0}, \pi, I\right)$ are given and $m \in M=\left\{m \in \mathbb{R}^{+}: l^{0} \leq m \leq u(m)\right\}$.

The objective function in equation (5) represents the private equity valuation of a representative investor with basis equal to the historical minimum stock price. The constraint (6) requires the proceeds from issuing $n^{1}(m)-1$ new shares and $D^{1}-D^{0}$ in new debt to cover the capital expenditure $I>0$. When $n^{1}<1$, the firm repurchases shares through brokers in the open market. Competitiveness of financial markets requires 
that the offer price of new securities equals their market price after issuance and there is no price reaction: $p^{0}(u(m), m)=p^{1}(u(m), m)$.

We will solve management's optimization problem using backward induction, starting with the valuation of securities after the real option exercise. After investment, equityholders receive a cash flow $\left(1-\tau^{e}\right)\left(x-c^{1}\right) / n^{1}$ per-share, as long as the firm is solvent. Therefore, in the region where it is not optimal to default (i.e., for $x>l^{1}(m)$ ), private equity valuations satisfy:

$$
\frac{\sigma^{2}}{2} x^{2} v_{x x}^{1}(x, m)+\mu x v_{x}^{1}(x, m)+\left(1-\tau^{e}\right)\left(x-c^{1}\right) / n^{1}=r v^{1}(x, m) .
$$

The right-hand side of equation (7) represents the return required by shareholders on their investment. The left-hand side represents the expected return, which comes in the form of changes in private valuation (first two terms) and dividends (third term). Equityholders may realize capital gains or losses at any time prior to default by selling their shares in return for after-tax proceeds $(1-\tau) p^{1}(x, m)+\tau B$. They may also choose to default on their debt obligations. As a result, equation (7) is solved subject to the following boundary conditions:

$$
\begin{aligned}
& v^{1}(x, m)=(1-\tau) p^{1}(x, m)+\tau B, \quad v_{x}^{1}(x, m)=(1-\tau) p_{x}^{1}(x, m) \quad \text { for } x=b^{1}(m ; B) . \\
& v^{1}(x, m)=0, \quad v_{x}^{1}(x, m)=0, \quad \text { for } x=l^{1}(m) \text {. }
\end{aligned}
$$

The first line in equation (8) captures the decision to sell the shares. The second line captures the decision to default. Importantly, Proposition 1 implies that the default boundary after investment satisfies $l^{1}(m)=b^{1}(m ; 0) \leq b^{1}(m ; B)$ for all $B \geq 0$. As a result, the boundary conditions related to the decision to default are subsumed in the boundary conditions related to the decision to sell shares, and we obtain the limited liability conditions $p^{1}\left(l^{1}(m), m\right)=p_{x}^{1}\left(l^{1}(m), m\right)=0$. Equations (5) and (10) can then be used to characterize the stock price explicitly in terms of $(x, m)$ (see the Appendix). Finally, the solution to $v^{1}(x, m)=\sup _{c^{1}, n^{1}} v^{1}\left(x, m ; p^{0}(m, m) \mid c^{1}, n^{1}\right)$ subject to the constraint $(6)$ determines the financing structure $\left(c^{1}(m), n^{1}(m)\right)$ at the time of investment.

Prior to investment, shareholders receive a cash flow $\left(1-\tau^{e}\right)\left(\pi x-c^{0}\right)$ and have to make three types of decisions. First, they may decide to invest at any time prior to default. Second, they may sell their shares in return for after-tax proceeds $(1-\tau) p^{0}(x, m)+$ 
$\tau p^{0}(m, m)$. Finally, they may choose to default on their debt obligations. As a result, the valuation equation corresponding to (5)-(6) is

$$
\frac{\sigma^{2}}{2} x^{2} v_{x x}^{0}(x, m)+\mu x v_{x}^{0}(x, m)+\left(1-\tau^{e}\right)\left(\pi x-c^{0}\right)=r v^{0}(x, m),
$$

which is solved subject to the following value-matching and smooth-fit conditions

$$
\begin{aligned}
& v^{0}(x, m)=v^{1}(x, m)-I, \quad v_{x}^{0}(x, m)=v_{x}^{1}(x, m), \quad \text { for } x=u(m) \\
& v^{0}(x, m)=0, \quad v_{x}^{0}(x, m)=0, \quad \text { for } x=m=l^{0}(m) \\
& v^{0}(x, m)=p^{0}(m, m), \quad v_{m}^{0}(x, m)=\frac{\tau}{1-\tau} v_{x}^{0}(x, m), \quad \text { for } x=m
\end{aligned}
$$

The first line in equation (10) determines the endogenous investment boundary $u(m)$. Shareholders' limited liability leads to the second pair of value-matching and smooth-fit conditions in equation (10) and determines the default trigger $l^{0}(m)$. The relevant default trigger is the one corresponding to a zero tax basis. The last two conditions in equation (10) come out of the investors' tax timing problem. For $B=p^{0}(m, m)$, the following optimality conditions for tax-loss selling hold at $x=m$ :

$$
v^{0}(x, m)=(1-\tau) p^{0}(x, m)+\tau p^{0}(m, m), \quad v_{x}^{0}(x, m)=(1-\tau)\left[p_{x}^{0}(x, m)+p_{m}^{0}(x, m)\right] .
$$

Applying the Envelope Theorem to the first condition in equation (11) and substituting in the second condition yields the last condition in equation (10).

Figure 1 illustrates the default $(\mathcal{L})$, continuation $(\mathcal{C})$, and investment $(\mathcal{U})$ regions for the manager's optimization problem. If $x>u(m)$ the firm invests immediately, and if $x<l^{0}(m)$ the firm defaults immediately. As a result, the continuation region in which the firm neither invests nor defaults is defined by $C=\left\{(x, m) \in \mathcal{S}: l^{0}(m) \leq x \leq u(m)\right\}$.

\section{[Insert Figure 1 Here]}

Denote by $\gamma$ and $\eta$ the positive and negative roots of the equation $\frac{1}{2} \sigma^{2} y(y-1)-\mu y-r=$ 0 and introduce the capitalization factors $\delta=\left(1-\tau^{e}\right) / r$ and $\lambda=\left(1-\tau^{e}\right) /(r-\mu)$. In addition, denote by $\varphi_{b}^{0}$ the present value of $\$ 1$ to be received the first time $X$ reaches the threshold $b^{0}(m ; B)$ before the investment trigger $u(m)$. Last, denote by $\varphi_{u}^{0}$ the present value of $\$ 1$ to be received the first time that $X$ reaches $u(m)$ before $b^{0}(m ; B)$. For 
$x \in\left[b^{0}(m ; B), u(m)\right]$, these state-contingent claims satisfy (see Revuz and Yor, 1999):

$$
\begin{aligned}
\varphi_{b}^{0}(x, m ; B) & =\frac{x^{-\gamma} u(m)^{-\eta}-x^{-\eta} u(m)^{-\gamma}}{\left(b^{0}\right)^{-\gamma} u(m)^{-\eta}-\left(b^{0}\right)^{-\eta} u(m)^{-\gamma}}, \\
\varphi_{u}^{0}(x, m ; B) & =\frac{x^{-\eta}\left(b^{0}\right)^{-\gamma}-x^{-\gamma}\left(b^{0}\right)^{-\eta}}{\left(b^{0}\right)^{-\gamma} u(m)^{-\eta}-\left(b^{0}\right)^{-\eta} u(m)^{-\gamma}} .
\end{aligned}
$$

We then have the following proposition.

Proposition 2 The private valuation of a share with basis $B\left(B \geq p^{0}(m, m)\right)$, respectively before and after investment, satisfies

$$
\begin{aligned}
v^{0}(x, m ; B)= & \lambda \pi x-\delta c^{0}+\varphi_{b}^{0}(x, m ; B)\left[B-\left(\lambda \pi b^{0}(m ; B)-\delta c^{0}\right)\right] \\
& +\varphi_{u}^{0}(x, m ; B)\left[v^{1}(u(m), m ; B)-\left(\lambda \pi u(m)-\delta c^{0}\right)\right], \\
v^{1}(x, m ; B)= & \frac{\lambda x-\delta c^{1}}{n^{1}}+\left(\frac{b^{1}(m ; B)}{x}\right)^{\gamma}\left[B-\frac{\lambda b^{1}(m ; B)-\delta c^{1}}{n^{1}}\right],
\end{aligned}
$$

In addition, the share price of equity, respectively before and after investment, satisfies

$$
\begin{aligned}
& p^{0}(x, m)=\frac{1}{1-\tau}\left[\int_{m}^{x} g(x, m, z) d z+f(x, m) \int_{l^{0}}^{m} h(m, z) d z\right], \\
& p^{1}(x, m)=\frac{\beta \lambda x-\delta c^{1}}{n^{1}}-\left(\frac{l^{1}(m)}{x}\right)^{\frac{\gamma}{1-\tau}}\left[\frac{\beta \lambda l^{1}(m)-\delta c^{1}}{n^{1}}\right]
\end{aligned}
$$

where $\beta=(1+\gamma) /(1+\gamma-\tau)$, and the functions $f(x, m), g(x, m, z)$ and $h(m, z)$ are defined in the Appendix. In these equations, the default threshold that maximizes shareholder value after investment is given by

$$
l^{1}(m)=\frac{\gamma}{1+\gamma} \frac{r-\mu}{r} c^{1}(m)
$$

Proposition 2 shows that private equity valuations have two components - the present value of dividend distributions and the present value of the stream of capital loss offsets. Shareholders receive the after-tax flow of dividends $\left(1-\tau^{e}\right)\left(\pi X_{t}-c^{0}\right)$ before investment and $\left(1-\tau^{e}\right)\left(X_{t}-c^{1}\right) / n^{1}$ per share after investment. Accordingly, the first terms in equations (14) and (15) are the after income-tax values of the perpetual dividend flow. Once operating income falls to $b^{i}\left(M_{t} ; B\right)$, investors with basis $B$ sell their shares. They receive after-tax proceeds equal to $B$ per share. The second term in equations (14) and (15) represents the value of this timing option, including the value of limited liability. The 
third term in equation (14) reflects the value of the real option to invest and restructure. The value of this option is the product of two terms: the payoff of the option to invest, $v^{1}(u(m), m ; B)-\left(\lambda \pi u(m)-\delta c^{0}\right)$, and the stochastic discount factor $\varphi_{u}^{0}(x, m ; B)$ representing the present value of $\$ 1$ to be received at the time of investment.

Consider next the firm's stock price. In equation (16), the first integral represents the after-tax value of dividend income plus the tax loss offsets until operating income falls to $m$. The second term captures the present value of the after-tax cash flows starting at the latter date and ending once shareholders make use of their limited liability. In equation (17), the first term represents the present value of future cash flows accruing to shareholders, ignoring the option to default. The second term represents the value of the option to default. In this equation, the coefficient $\beta$ captures the effects of capital gains taxes on prices. In addition, the price of a bankruptcy contingent claim is discounted due to the fact that investors collect capital loss offsets on the path to bankruptcy. This effect is captured by the exponent $\frac{1}{1-\tau}$.

The value of corporate debt can be derived using a similar approach (see the Appendix). The next proposition gives the value of the corporate debt after investment.

Proposition 3 The market value of aggregate debt after investment (and similarly of the old and new debt issues with $c^{1}$ replaced by $c^{0}$ and $c^{1}-c^{0}$, respectively) is

$$
D^{1}(x, m)=\frac{c^{1}\left(1-\tau^{p}\right)}{r}\left[1-\omega\left(\frac{l^{1}(m)}{x}\right)^{\frac{\gamma}{1-\tau}}\right],
$$

where $\omega \in(0,1)$ measures the total bankruptcy cost and is defined by

$$
\omega=1-\frac{1-\tau^{e}}{1-\tau^{p}} \frac{\gamma(1-\alpha)}{1+\gamma-\tau}
$$

The value of corporate debt reported in Proposition 3 takes the usual functional form (see e.g. Leland (1994)). The first factor on the right-hand side of equation (19) represents the value of risk-free debt. The second factor captures the impact of default risk on the value of corporate debt. This term incorporates both the loss $\omega$ incurred by debtholders in default and a stochastic discount factor $\left(l^{1}(m) / x\right)^{\frac{\gamma}{1-\tau}}$ that reflects the timing and the probability of bankruptcy. 
A comparison with some special cases to the general solutions (14)-(19) illustrates how personal taxes affect private valuations and market prices. When $c^{1}=0\left(n^{1}=1\right)$ and $\tau>0$, the valuations in period 1 coincide with the equations in Constantinides (1983) for the value of an unlevered firm. The basis reset trigger $b^{1}(m ; B)$ equals $B /(\beta \lambda)$ and

$$
\begin{aligned}
v^{1}(x, m ; B) & =\beta^{-1} p^{1}(x, m)+\left(1-\beta^{-1}\right) B^{1+\gamma} p^{1}(x, m)^{-\gamma} \\
p^{1}(x, m) & =\beta \lambda x .
\end{aligned}
$$

When $\tau=0$, the value of the tax option vanishes and private valuations (14) and (15) coincide with the share prices (16) and (17). Expressions $(15,17)$ and (19) collapse to the values of equity and debt in Leland (1994). The investment trigger $u(m)$ becomes time-independent. The stock price is independent of $m$ and given by

$$
\begin{aligned}
p^{0}(x, m)= & \pi \lambda x-\delta c^{0}-\frac{x^{-\gamma} u^{-\eta}-u^{-\gamma} x^{-\eta}}{\left(l^{0}\right)^{-\gamma} u^{-\eta}-u^{-\gamma}\left(l^{0}\right)^{-\eta}}\left(\pi \lambda l^{0}-\delta c^{0}\right) \\
+ & \frac{\left(l^{0}\right)^{-\gamma} x^{-\eta}-x^{-\gamma}\left(l^{0}\right)^{-\eta}}{\left(l^{0}\right)^{-\gamma} u^{-\eta}-u^{-\gamma}\left(l^{0}\right)^{-\eta}}\left[p^{1}(u, m)-\left(\pi \lambda u-\delta c^{0}\right)\right], \\
p^{1}(x, m)= & {\left[\lambda x-\delta c^{1}-\left(l^{1}\right)^{\gamma} x^{-\gamma}\left(\lambda l^{1}-\delta c^{1}\right)\right] / n^{1} . }
\end{aligned}
$$

\section{Personal Taxes, Investment, and Financing}

This section examines the effects of personal taxes on investment and financing decisions as well as the properties of the default policy selected by management. It also discusses the benefits of switching to corporate policy choices that reflect capital gains taxes.

\subsection{Distortions in investment policy}

A standard result in real options theory is that uncertainty and irreversibility give rise to an option value of waiting so that firms invest only once a project's rate of return exceeds the cost of capital by a potentially large option premium. The option value of waiting arises solely from the desire to avoid bad outcomes, i.e., unprofitable states. Capital loss offsets increase investors' after-tax payoffs in states where the firm's stock price performs poorly, presumably when operating performance is bad, while leaving payoffs in good states unaffected (where it is not optimal for shareholders to sell shares). The asymmetric taxation of gains (good news) and losses (bad news) limits potential losses and thereby 
diminishes the option value of waiting. This leads firms with high-basis shareholders to impose a lower hurdle rate - fostering investment. ${ }^{9}$

This investment stimulus is transitory in nature. When investors reset their tax basis after stock price declines, the inherent tax asymmetry gradually disappears. The firm's optimal response is to raise the hurdle rate for investment any time its shareholders reset. As a result, the optimal investment threshold shifts up whenever the stock price reaches a new low. The resulting distortions in corporate investment are substantial since capital loss offsets kick in when the opportunity cost of investing is the highest.

\section{[Insert Figure 2 Here]}

Figure 2 illustrates the effect of personal taxes on the timing of investment. The figure plots a sample path for the firm's operating income or, equivalently, the firm's stock price. The top line on this figure corresponds to the investment trigger $u(m)$. The bottom line corresponds to the default trigger $l(m)$. Whenever taxable shareholders realize losses because of a drop in the stock price below their current basis, the tax basis gets reset downward as illustrated by the middle line. The optimal response for the firm is to shift the investment trigger (top line) upward, delaying investment further. As we show below, the firm also starts using more equity to fund investment.

To examine the quantitative implications of personal taxes for investment and financing, we need to select values for the parameters of the model. The numerical values for the parameters $r, \mu, \sigma, \omega, \tau, \tau^{c}, \tau^{d}, \tau^{p}$ are summarized in Table 1. They are a consensus of values found in the literature and in the tax code. Importantly, two opposing views on the appropriate value for $\tau^{e}$ exist in the literature. Miller (1977) argues in a static setting that, in the absence of a lock-in effect, tax clienteles lead to $\tau^{e}=\tau^{p}$. By contrast, Constantinides (1983) shows in a dynamic setting with realization-based taxation that a lock-in effect arises because investors have the incentive to minimize their tax bill

\footnotetext{
${ }^{9}$ Both the marginal value of exercising the growth option and the marginal value of waiting depend on the tax basis. At the optimal investment date the marginal value of exercising the option and the marginal value of waiting must be equal. Inevitably, the investment threshold depends on the tax basis of the firm's owners. The effects of the basis on the investment threshold depend on the financial policy. Optimal financing is sufficient for the investment boundary to be monotonically decreasing in $B$.
} 
through the timing of their portfolio trades. The empirical findings in Graham (1999, 2000) support this view and justify $\tau^{e}>\tau^{p}$.

\section{[Insert Table 1 Here]}

Table 2 reports comparative statics for the investment trigger $u(m)$ as a function of stock price performance. Each line in the table represents an alteration of the base case. Across the different columns the state variable $m$ varies within the interval $\left[l^{0}, \bar{m}\right]$, where $\bar{m}=\sup \left(m \in R^{+}: u(m) \geq m\right)$, corresponding to basis-price ratios (BP $P^{\text {-ratio}) ~ o f ~ z e r o, ~}$ one half, and one at the investment date. The second panel in Table 2 characterizes the investment policy in terms of market-to-book ratios (of equity) at the investment date.

[Insert Table 2 Here]

The common feature in all parameter settings is that the investment trigger $u(m)$ shifts upward as $m$ falls. In the base case environment, $u(m)$ is more than twice as high for a $B P_{u}$-ratio of zero compared to a $B P_{u}$-ratio of one. The table also shows that capital gains taxes have a large effect on investment decisions when the $B P_{u}$-ratio is high, since the hedge provided by capital loss offsets is greater when the basis of incumbents is high. This effect is illustrated by the left panel of Figure 3 .

\section{[Insert Figure 3 Here]}

The comparative statics results reported in Table 2 imply that events that cause the stock price to fall and shareholders to realize losses, such as poor operating performance or negative macroeconomic shocks, have a long-term impact on capital budgeting decisions. Short-term stock price fluctuations lead to long-term reductions in investment rates (and leverage ratios). Investment depends positively on past profitability and cash flows, consistent with the empirical evidence in Fazzari, Hubbard, and Petersen (1988) (see also section 5 below). The corporate inertia documented in Welch (2004) is more pronounced after poor performance associated with stock price declines (Strebulaev (2007) provides a rationale for inertia in financing based on the flotation costs of securities).

Another way to look at the investment distortions induced by capital gains taxes is to examine the hurdle rate for investment. Given the dynamics of the firm cash flows 
in equation (1) and a value $u(m)$ of the cash flow shock at the time of investment, the internal rate of return on the project $H R_{\tau}$ satisfies for an unlevered firm (using equation $(21))$ :

$$
(1-\pi)\left\{\frac{\left(1-\tau^{e}\right) u(m)}{H R_{\tau}-\mu}+\left(1-\beta^{-1}\right) B^{1+\gamma}\left[\beta \frac{\left(1-\tau^{e}\right) u(m)}{H R_{\tau}-\mu}\right]^{-\gamma}\right\}=I .
$$

The left-hand side of this equation gives the present value of the cash flows from the project at the time of investment. The right-hand side gives the cost of investment. By changing the investment threshold $u(m)$, capital gains taxes change the hurdle rate for investment $H R_{\tau}$. In the base case environment, the hurdle rate for investment is 50 percent higher for a $B P_{u}$-ratio of zero compared to a $B P_{u}$-ratio of one.

\subsection{The trade-off theory with personal taxes}

The above analysis shows that firms owned by taxable investors with low basis should underinvest relative to firms owned by high-basis investors. Because of its impact on private valuations, the lock-in effect of capital gains taxes also has an impact on financing choices. In particular, we have the following result.

Proposition 4 Firms use more equity to fund their investment project when the tax basis of their shareholders is lower. That is $\partial c^{1}(x \mid B) / \partial B \geq 0$, for any given $x$ and $c^{0}$.

In the limit as the basis-price ratio approaches one and $c^{0}=0$, the target leverage ratio in the seasoned offering is given by

$$
\text { Target Leverage }=\frac{\left(1-\tau^{p}\right) \vartheta\left[1-\omega \vartheta^{\frac{\gamma}{1-\tau}}\right]}{\frac{\gamma}{1+\gamma-\tau}\left[1-\tau^{e}+\vartheta\left(\tau^{e}-\tau^{p}\right)\right]},
$$

where $\omega$ is defined in Proposition 3 and $\vartheta$ satisfies

$$
\vartheta=\left[\frac{(1-\tau)\left(\tau^{e}-\tau^{p}\right)}{(1+\gamma-\tau)\left(\tau^{e}-\tau^{p}\right)+\alpha \gamma\left(1-\tau^{e}\right)}\right]^{\frac{1-\tau}{\gamma}}
$$

The basic mechanism driving the results in Proposition 4 is a valuation gap between investors with different tax basis. The ex-ante financing choice balances debt tax shields, default costs, and the income effect of capital gains taxes, which is just that tax payments, tax loss offsets and credits are compounded into pre-tax valuations. 
In the seasoned offering, the target leverage ratio reflects in addition the tax-arbitrage effect of realization-based capital gains taxation. This personal tax arbitrage arises from a wedge between the stock price and the private valuations of incumbent investors. Since the embedded tax timing option is more valuable the larger the investors' tax basis, incumbents have lower private valuations than new investors whenever the share price exceeds the basis of incumbents. This valuation gap generates a surplus when raising external funds. Every newly issued share entitles new investors to an at-the-money tax option provided by the government. Issuing equity therefore constitutes a local tax arbitrage for incumbent shareholders similar to issuing debt for interest tax shield purposes. ${ }^{10}$ Since the reservation value of low-basis owners is lower, they extract a larger surplus than high-basis owners - even though the ownership dilution associated with new equity issues and the funds raised per share are the same. The firm's management takes these effects into account by issuing more equity the larger the stock price-to-basis ratio. As shown in Proposition 4, this leads to a negative relation between the target leverage ratio and the price-to-basis ratio.

\section{[Insert Table 3 Here]}

Table 3 quantifies the cross-sectional variation in ex-post capital structures resulting purely from personal tax considerations. The table reports both the leverage ratio and the credit spread at the issuance date. The comparative statics on equity issuance and the equity-debt mix exhibit the same pattern and are omitted. Input parameter values for the base case environment are reported in Table 1. Panel A in Table 3 reveals that the cross-sectional dispersion in target leverage ratios can reach 63 percentage points. In our base case, firms with shareholders that have a negligible tax basis (e.g., due to prior loss realizations or little IPO proceeds) have a target leverage of 47.6 percent compared to 64.3 percent for firms with a basis-price ratio of one at the restructuring date. As shown in Panel B of Table 3 this translates into a yield on corporate debt for the zero-basis firms that is 62 basis points lower than for the highest basis firms. The table also shows that

\footnotetext{
${ }^{10}$ The surplus is equal to the difference between the reservation values of new investors (i.e., the competitive market price) and incumbent shareholders (i.e., private valuations). In competitive markets, incumbents capture the entire surplus. The surplus also depends on the use of the proceeds since the value of the timing option is an increasing function of cash flows volatility (see Ross, 1987).
} 
capital gains taxes have a large effect on financing decisions when the basis-price ratio is low, since the arbitrage effect of realization-based capital gains taxation is greater when there is a larger difference between the basis of incumbents and the market price for new investors. This effect is illustrated by the right panel of Figure 3.

\subsection{Capital gains taxes and the timing of default}

When the decision to default is endogenous, the timing of default depends on the default threshold selected by management. Figure 4 plots the firm's default boundary before (solid) and after (dashed) exercise of the real option in separate panels for different parameter values. The figure shows that after investment (see also Proposition 3), the default threshold $l^{1}$ does not depend on the capital gains tax rate $\tau$. The intuition for this result is that shareholders have reset their tax basis to nil by the time of default. Once the basis is zero, valuations are independent of the capital gains tax rate (this can be seen by setting $B=0$ in equation (15)). As a result, the default threshold $l^{1}$ is independent of $\tau$.

\section{[Insert Figure 4 Here]}

Before investment, the default threshold reflects not only the trade-off between the continuation value of assets in place and the firm's debt obligations but also the impact of the decision to default on the value of the firm's growth option. In this respect, our paper is related to the papers by Sundaresan and Wang (2006) and Lobanov and Strebulaev (2007), in which the default threshold before investment reflects the real option value of waiting. The comparative statics reveal that the default boundary before investment lies well below the corresponding value after investment because the loss of a valuable investment opportunity discourages shareholders from declaring bankruptcy. Importantly, since capital gains taxes affect the investment threshold $u(m)$, the default threshold prior to investment indirectly reflects the tax status of the firm's shareholders and, therefore, depends on the capital gains tax rate $\tau$ and the personal income tax rates $\tau^{p}, \tau^{d}$.

\subsection{The relevance of personal taxes to capital budgeting}

The analysis reported above shows that the distortions in investment and financing policies induced by capital gains taxes are economically significant. One question that natu- 
rally arises is whether they are also economically relevant. We can answer this question by examining the change in value created by a switch from time-independent investment and financial policies to path-dependent policies. This change in value is reported in Table 4. The numbers reported in the table are computed at the market value maximizing trigger and, thus, measure the opportunity cost of maximizing the stock price.

\section{[Insert Table 4 Here]}

As shown in Table 4, the benefit from switching to the path-dependent policy in the base case environment can represent up to $3.4 \%$ of firm value, depending on the owners' tax basis. For a basis equal to the stock price the two policies are identical, offering no gains. They differ the most for a basis-price ratio of zero, offering the largest gains. For capital restructurings the optimal policy yields a $5.6 \%$ value gain (when $\pi \approx 100 \%$ ). Across parametrizations the improvement in value reaches up to $14.2 \%$.

\subsection{Managerial discretion and capital gains taxes}

So far we have assumed that the objective of management was to maximize the private valuations of shareholders. Assume now that the manager does not act in the best interest of shareholders so that the relevant tax basis is the manager's tax basis. Let us denote by $B$ this tax basis and consider, as in Zwiebel (1996) and Morellec (2004), that management has discretion over investment and financing policies. In this case, the optimization problem of the manager is similar to (7)-(10) with $B$ replacing $m$ everywhere. ${ }^{11}$ The solution to this optimization problem can then be derived using the same steps as above.

\footnotetext{
${ }^{11}$ In the United States, wash-sale rules prevent shareholders from selling a stock and repurchasing the same stock within 30 days (otherwise the tax-loss credit is lost). This implies that in our setting the manager loses control for 30 days. To see whether wash-sale rules can have an impact on the policy choices of management, we can compute the probability that a restructuring occurs within 30 days of a stock sale. An upper bound for this probability (that should take into account the fact that $u(m)$ goes up as the state variable goes down) is given by the probability of reaching the threshold $u(m)$ starting from $b^{0}(m ; B)$ over a 30-day period:

$$
\begin{aligned}
\mathbb{P}\left(\sup _{0 \leq t \leq T} X_{t} \geq u(m)\right)= & \mathcal{N}\left[\frac{-\ln (u(m) / b(m ; B))+\mu_{S} T}{\sigma \sqrt{T}}\right] \\
& +\left(\frac{u(m)}{b(m ; B)}\right)^{\frac{2 \mu_{S}}{\sigma^{2}}} \mathcal{N}\left[\frac{-\ln (u(m) / b(m ; B))-\mu_{S} T}{\sigma \sqrt{T}}\right],
\end{aligned}
$$
}


Table 5 compares the investment and financing policies selected by the manager with the policies that would be selected if the manager's tax basis was ignored. The table reports the change in investment policy, the change in the firm's target leverage ratio, and the improvement in private valuations associated with policy choices that reflect the tax basis of the manager.

\section{[Insert Table 5 Here]}

The results reported in Table 5 are similar to those reported in Tables 2, 3, and 4. Specifically, Table 5 shows that managerial discretion leads to an increase in the investment threshold and to a decrease in the leverage ratio. The benefit for the manager of switching to a policy reflecting his tax basis ranges between $0.2 \%$ and $6.7 \%$ of private valuations.

\subsection{The effects of trading frictions}

The analysis so far has ignored the effects of trading frictions (such as transaction costs) on shareholders' incentives to sell their shares and reset their basis following capital gains losses. Arguably, these frictions may have an impact on the value-maximizing policy choices in the presence of capital gains taxes.

To investigate this issue, we consider four alternative environments. In the first environment, we assume that the manager cannot trade at any point in time (due to restrictions in his compensation contract) so that the only effect of capital gains taxes is to provide a tax credit to the decision maker at the time of default. By contrast new investors are allowed to trade as in the baseline model so that the dynamics of asset prices are unaffected by the trading restriction faced by the manager. In the second environment, we consider as in Liu and Loewenstein (2008) that when shareholders want to sell their shares, they can sell their stock at the price $p_{T}^{i}(x, m)=(1-\rho) p^{i}(x, m)$ where $\rho=\mathbf{c}\left(1-B / p^{i}(x, m)\right)$ with $0 \leq \mathbf{c} \leq 1$ represents the transaction cost rate. In this case, the optimization problem of the decision maker is similar to (7)-(10) with $p_{T}^{i}(x, m)$ replacing $p^{i}(x, m)$ everywhere. In the third environment, we consider that neither the manager nor shareholders can trade. Finally, we consider in the fourth environment that

where $T=1 / 12, \mu_{S}=\mu-\sigma^{2} / 2$, and $\mathcal{N}$ is the Standard Normal CDF. When the basis-price ratio of the manager is 0.5 , the probability of investment over 30 days is less than $1 \%$ if the volatility of cash flows $\sigma$ is lower than $75 \%$, showing that wash-sale rules should have little impact on management's policy choices. 
both the manager and shareholders can trade at a cost.

[Insert Table 6 Here]

Panels A, B, C, and D of Table 6 report the firm's investment trigger and target leverage ratio for environments $1,2,3$, and 4 respectively. In panels B and D, we calibrate the value of $\mathbf{c}$ in such a way that we get a reduction in the stock price equivalent to the illiquidity discount computed by Lo, Mamaysky, and Wang, 2006, or Liu and Lowenstein, 2008, for a proportional transaction cost rate of 1\% (as documented in Ang and Bekaert, 2002). The results reported in Table 6 are similar to those reported in Tables 2 and 3. In particular, the table shows that in each environment the selected investment threshold decreases and the firm's target leverage ratio increases with the basis-price ratio. This suggests that trading frictions have no qualitative and small quantitative effects on the firm's policy choices.

\section{Empirical Analysis}

In this section we test the predictions of the model regarding corporate investment and financing policies using a powerful difference-in-difference strategy for a large sample of US industrial firms that are owned by taxable investors. The main prediction from our model for corporate investment is that firms owned by taxable investors with low basis underinvest compared to high-basis firms, all else equal. As a result, we expect to observe a positive relation between corporate investment and the tax basis of investors, controlling for other factors that are known to affect investment. Similarly, the main prediction from the model for corporate financing is that firms owned by low-basis investors use more equity financing to fund investment compared to high-basis firms. Personal taxes are levied on the income reported by individual investors (and firms) only. Many institutional investors are tax-exempt. We therefore expect the tax basis to be irrelevant for corporate decisions when firms are held largely by tax exempt investors.

A simple test of personal tax effects can be constructed by looking at whether shareholders' tax basis has significant bearing on investment and financing decisions. The caveat is that the tax basis, while known to investors, is not directly observable. In 
our empirical analysis, we therefore resort to reasonable proxies for the tax basis and check for robustness. We find that our various proxies for investors' tax basis have economically and statistically significant explanatory power for corporate investment and financing. Overall, our empirical analysis provides new evidence on corporate investment and financing decisions that is strongly supportive of the model's predictions.

\subsection{Data and sample construction}

Our main sample consists of all COMPUSTAT firms for which data on the IPO date and offer price are available. Knowing the IPO date and price allows us to study the implications of the model from a common starting point, to track the tax basis of investors with reasonable precision, and to make our findings comparable to the recent evidence on investment dynamics and the evolution of leverage. The initial sample consists of all IPOs between January 1, 1970, and March 31, 2008, reported by the Securities Data Company (SDC, now owned by Thomson Reuters). Following the literature, we exclude from the sample spinoffs, unit offers, financial firms with SIC codes between 6000 and 6999, and public administration with SIC codes between 9000 and 9999. Firms are included in the sample until 15 years after the IPO or until they exit COMPUSTAT. The data end with fiscal year 2007. (For consistency with prior studies, we have also investigated the sample restricted to end with fiscal year 2002. We have obtained the same results.)

The construction of the dependent and explanatory variables follows the literature. Total assets, $A$, are given by COMPUSTAT Annual Item 6 . Book debt, $D$, is defined as total liabilities (Item 181) and preferred stock (Item 10, replaced by the redemption value of preferred stock (Item 56) when missing) minus deferred taxes (Item 35) and convertible debt (Item 79). Book equity, $E$, is total assets minus book debt. Book leverage, $D / A$, is defined as book debt divided by total assets. Market-to-book ratio, $M / B$, is book debt plus market equity (common shares outstanding (Item 25) times share price (Item 199)) divided by total assets. Market-to-book ratios larger than ten are eliminated for consistency with prior studies. The external finance weighted-average market-to-book ratio, $M / B^{e f w a}$, is defined as in Baker and Wurgler (2002, equation (3)).

Investment denotes capital expenditures during the fiscal year (Item 128) normalized by total assets $A$ at the beginning of the fiscal year. Net equity issues, Equity Issuance, is 
the change in book equity minus the change in retained earnings (Item 36) normalized by total assets at the beginning of the fiscal year. Profitability is measured by EBITDA/A, which is earnings before interest, taxes, and depreciation (Item 13) divided by fiscal year-end total assets. Size is the logarithm of net sales (Item 12). Asset tangibility, Tangibility, is defined as net plant, property, and equipment (Item 8) over total assets. $R \& D$ is research and development expense (Item 46, replaced by zero when missing) over total assets. A dummy variable, $R D D$, takes the value of one when Item 46 is missing and zero otherwise. In the analysis that follows, we lag all explanatory variables by one fiscal year. Firm-year observations that are outliers with regard to various firm characteristics

are adjusted for by winsorizing the data at .5\% and $99.5 \%$. Our final sample consists of more than 30,000 firm-year observations in 5,570 IPOs.

[Insert Table 7 Here]

Panel A of Table 7 provides descriptive statistics for the firm characteristics and corporate decisions. All variables except $M / B$ and Size are expressed in percentage terms. We define the IPO year as the fiscal year in which the IPO takes place. Year IPO $+k$ is then the $k^{\text {th }}$ fiscal year after the IPO. The patterns displayed in Table 7 are consistent with the findings in previous studies. Investment and issuance activity decline with age. The financing mix is relatively stable. Size increases with age, whereas the market-tobook ratio decreases over time. Cash flows and profitability decline substantially over the two years following the IPO year, and strongly increase thereafter. Last, the individual ownership share slightly increases with firm age.

\subsection{Proxies for investors' tax basis}

The tax basis of shareholders is not directly observable. We therefore construct proxies for the tax basis of incumbents using information on the IPO offer price (typically a large portion of the float is purchased at this price so that the initial tax basis equals the IPO offer price), the evolution of the stock price in financial markets after the IPO, the share volume and stock turnover, and the tax-relevant changes to the float, such as stock splits and reverse splits. The history of price and transaction volume information on the firms' common shares and the number of shares outstanding at each point in time are obtained 
from CRSP. The number of outstanding shares are then used to compute measures of share turnover. When computing the tax basis, we adjust stock prices for stock splits using the adjustment factors provided by CRSP.

The most natural proxy for shareholders' tax basis given the model described in section 2 is the running minimum of the stock price (as in Constantinides, 1983):

$$
B_{t}=\min \left(P_{I P O}, \min _{s=1,2, \ldots, t} P_{s}\right),
$$

where $P_{I P O}$ is the IPO offer price and $P_{t}$ denotes the secondary market price at date $t$ after the IPO. We use equation (28) to construct our basic measure (which corresponds to Constantinides' frictionless trading model). The measure for embedded capital gains used in Dai, Maydew, Shackelford, and Zhang (2008), i.e., the stock price appreciation over the past two years, is similar to the price-basis ratio constructed from our measure but neglects transitory price drops.

An alternative to the model described above is the proportional trading model of Lewellen and Lewellen (2006), which assumes that all investors holding stock are equally likely to trade, regardless of tax status, time of purchase, and market conditions. Under this assumption, we can infer tax-induced trading from observed trading volume and recursively estimate the firm's tax basis using aggregate trading volume data, given an estimate of the initial tax basis. Lewellen and Lewellen (LL, 2006), however, acknowledge that proportional trading may constitute an overly restrictive and probably inaccurate assumption. It is generally agreed that long-term investors that are active in corporate governance trade less often than short-term speculators and, hence, make up a small fraction of share turnover at normal times. Aggregate trading volume thus may constitute a poor proxy for trading by tax sensitive investors.

To reconcile the two extreme views about trading activity by taxable investors, we allow the (trading) hazard rates of short- and long-term investors to vary across market conditions. Adopting the recursive formulation in LL (2006) one can write the basis at time $t$ as:

$$
B_{t}=P_{t} * w_{t}+B_{t-1} *\left(1-w_{t}\right),
$$

where $w_{t}$ is a weight that is time- and stock-specific. We set the initial basis to $P_{I P O}$. The weights $w_{t}$ depend on our assumption about the composition of trading amongst short- 
term and long-term investors in up and down markets. (The measure used by Grinblatt and Han, 2005, is similar to ours but sets the initial basis to the trading price five years before the current date - so that the two measures perfectly coincide any date between the IPO and IPO +5 years but differ afterwards).

Our basic model (equation (28)) neglects any information contained in aggregate volume and sets $w_{t}=1$ if the stock price goes down and $w_{t}=0$ otherwise. Our alternative tax basis proxies are defined as follows. First, to capture trading frictions, we assume that shareholders do not reset the tax basis instantly but slowly and in proportion with all investors (Basis proxy II). The proportional trading assumption then holds only on the way down, corresponding to $w_{t}=$ Turnover $_{t-1, t}$ if the stock price goes down and $w_{t}=0$ otherwise. In this specification, Turnover $_{t-1, t}$ is defined as shares traded between date $t-1$ and $t$ divided by the number of shares outstanding. We cap turnover at $100 \%$ of shares outstanding so that the weights are between zero and one. Second, to capture trading frictions and tax-unrelated trading, we define Basis proxy III using the following weights: $w_{t}=.5 *\left(1+\right.$ Turnover $\left._{t-1, t}\right)$ if the stock price goes down and $w_{t}=.5 *$ Turnover $_{t-1, t}$ otherwise (we have used other specifications with the same results).

To summarize, we construct the following set of proxies for shareholders' tax basis:

- Proxy I: $w_{t}=1$ if the stock price goes down and 0 otherwise.

- Proxy II: $w_{t}=$ Turnover $_{t-1, t}$ if the stock price goes down and 0 otherwise.

- Proxy III: $w_{t}=.5 *\left(1+\right.$ Turnover $\left._{t-1, t}\right)$ if the stock price goes down and $.5 *$ Turnover $_{t-1, t}$ otherwise.

In each specification, we normalize the tax basis cross-sectionally by dividing through by the IPO offer price. Thus, the explanatory variable used in the analysis is defined as Tax Basis $/ O_{t}=B_{t} / P_{I P O}$. Similarly, we define the explanatory variable Stock Price $/ O_{t}$ as the share price at date $t, P_{t}$, divided by the IPO offer price. Panel B of Table 7 provides descriptive statistics on the various tax basis proxies used in the empirical analysis. 


\subsection{Do personal taxes affect corporate investment?}

To examine the effects of capital gains taxes on corporate investment, we augment standard investment regressions with our tax basis proxy. The dependent variable, Investment $_{t}$, is the total investment during the fiscal year $t-1$ through $t$ normalized by beginning of-the-year assets. In these regressions, we use the components of the basisprice ratio, lagged one year, as explanatory variable instead of using the basis-price ratio. The reason is that the stock price contains information about investment opportunities. Separating the basis-price ratio into basis and price component, both appropriately normalized, provides us with a cleaner proxy for tax effects. In the robustness checks (Panel B), we use the basis-price ratio, Basis-Price Ratio Pr-1 $_{-1}$, as explanatory variable. We obtain similar results. Dropping the price component also does not affect the results.

When running these regressions, we are interested in determining whether the investors' tax basis, expressed in percent of the respective IPO offer price, is a determinant of investment when controlling for the current (normalized) stock price and other firm characteristics that are known to affect corporate investment. The set of regressions we perform is of the following form:

$$
\begin{aligned}
\text { Investment }_{t}= & c_{0}+c_{1} \text { Tax Basis } / O_{t-1}+c_{2} \text { Stock Price } / O_{t-1} \\
& +c_{3} M / B_{t-1}+c_{4} C_{t-1}+c_{5} \text { Tangibility }_{t-1}+c_{6} \text { Size }_{t-1} \\
& \quad+c_{7} \text { Profitability }_{t-1}+c_{8} R \& D_{t-1}+c_{9} R D D_{t-1}+\epsilon_{t} .
\end{aligned}
$$

In this regression, we expect a positive coefficient $c_{1}$, implying that high basis firms invest more than low basis firms. Table 8 reports the results. The regressions in Panel A are estimated with firm fixed effects. We adjust standard errors for clustering at the industry level defined by three-digit SIC codes (as suggested by Petersen, 2008). The coefficients on $M / B_{t-1}, C F_{t-1}$, Tangibility Ta $_{-1}$, Size $e_{t-1}$, Profitability $t-1, R \& D_{t-1}$, and $R D D_{t-1}$ are as expected and consistent with prior studies. The coefficient $c_{1}$ on Tax Basist-1 is positive and statistically significant. This is consistent with our hypothesis that low basis firms should underinvest relative to high basis firms.

[Insert Table 8 Here] 
In panel B, we perform a number of robustness checks. First, we estimate the regressions with random effects or using instrumental variables and fixed effects. The coefficient $c_{1}$ is again positive and significant. In this panel, we also replace Tax Basist-1 and Stock Price $_{t-1}$ by their ratio Basis-Price Ratio ${ }_{t-1}$, so that we do not estimate separately $c_{1}$ and $c_{2}$. The results we obtain are generally consistent with Panel A. Notably, the coefficient $c_{1}$ on Basis-Price Ratiot-1 is typically positive and significant (the only exception is for basis proxy II). Taken together, this first round of results provides evidence that the tax basis of investors has a systematic effect on corporate investment.

Another way to test our model is to investigate the impact of the shareholders' tax basis on the probability of large corporate investments, defined as $P\left(\right.$ Investment $\left._{t} \geq \widehat{I}\right)$ where $\widehat{I}$ represents the threshold for large investments (Panel C: Logit analysis). For

this analysis, we need to define "large" investments. We define the threshold $\widehat{I}$ for large investments as the average industry investment rate in the sample (similar results are obtained if we use instead the median investment rate). The specifications are estimated with fixed or random effects. The significant positive coefficient on the tax basis (except for basis proxy III) suggests again that high basis firms are more likely to conduct real investments, consistent with the model's prediction.

\subsection{Proxies for tax sensitive stock ownership}

Capital gains taxes apply to income reported by individual investors on their personal tax filings. This includes capital gains from the selling of shares held by individuals directly and shares held indirectly in flow-through entities such as mutual funds, partnerships, trusts, and limited liability corporations that pass-through dividend income. Capital gains taxes are not levied on tax-deferred accounts in qualified retirement plans (i.e., pension, IRA, 401k). Tax-exempt organizations including pension funds, universities, charities, and other non-profits (plus foreigners) also do not pay capital gains taxes, while corporations do pay capital gains taxes.

If our proxy for shareholders' tax basis indeed captures personal tax effects, we should expect the significance of $c_{1}$ to disappear when restricting the sample to firms for which personal taxes are irrelevant due to their ownership structure. To test this hypothesis, we construct proxies for the ownership share of a company by tax sensitive investors 
using data on shares held by institutional investors as a fraction of shares outstanding. ${ }^{12}$ Data on ownership shares are obtained from quarterly filings by registered investment management companies and professional money managers with the U.S. Securities and Exchange Commission on Form 13f (known as CDA/Spectrum S34 data and provided through Thomson Reuters). ${ }^{13}$ The data identifies the type of institutional manager using broad categories. ${ }^{14}$ The types of investment companies that are required to file with the SEC (often called 13f institutions) include banks, insurance companies, parents of mutual funds, pension funds, university endowments, and numerous other types of professional investment advisors. When measuring institutional ownership, we employ information on shares outstanding provided by Thomson, while we use the CRSP data for measuring turnover, since the data can be recorded at different times and for consistency within data base. The two measures differ by less than ten percent in 90 percent of cases.

Following Dai, Maydew, Shackelford, and Zhang (2008), we measure both direct and total holdings by individual investors and compute two measures of the tax sensitive ownership on a stock at any point in time:

\footnotetext{
${ }^{12}$ Dai, Maydew, Shackelford, and Zhang (2008) and Ayers, Lefanowicz, and Robinson (2003), among others, have previously used institutional holdings to determine the fraction of shares held by individuals. An alternative source of information on tax sensitive holdings are the insider filings with the SEC as reported on Forms 3, 4, 5, and 144. Insider holdings are often subject to holding period restrictions and trading blackout periods. We have therefore opted to focus on holdings by all individuals.

${ }^{13}$ Under Securities Exchange Act Section 3(a)(9) and Section 13(f)(5)(A), an institutional investment manager is an entity that either invests in, or buys and sells, securities for its own account; or a natural person or an entity that exercises investment discretion over the account of any other natural person or entity. Currently, only managers with over $\$ 100$ million under their control are required to file, but others may still do so and be included in the CDA/Spectrum S34 data set. Other cases where holdings are not reported include cases with confidentiality issues and holdings that can not be matched to a master security file. Cases where two or more managers share control are counted only once (the SEC requires only one of the managers to report holdings information in their $13 \mathrm{f}$ reports). These rules and regulations imply that equity holdings by institutions that are not captured include small holdings under 10,000 shares or $\$ 200,000$ and all holdings by managers controlling less than $\$ 100$ million if they choose not to report under Securities Exchange Act Section 3(a)(9) and Section 13(f)(5)(A).

${ }^{14}$ The Thomson type code identifying institutional managers as banks, insurance companies, investment companies, and independent investment advisors reflects a known mapping error in 1998 and beyond. We try to mitigate the classification error by searching over the entire database prior to 1998 and imputing the type code for the improperly classified institutions after 1997.
} 
- Direct individual ownership = Shares outstanding minus total institutional holdings (Thomson type codes 1-5), divided by shares outstanding.

- Total individual ownership = Direct individual holdings plus holdings by mutual funds (Thomson type code 3), divided by shares outstanding.

Table 9 reports the results when we estimate the basic investment regression separately for firms owned predominantly by individual investors or institutional investors, respectively. For this purpose, we split the sample into firms with $80 \%$ or more, $50 \%$ to 80\%, and less than 50\% individual ownership. Each column corresponds to an ownership cluster. Panel A splits the sample of firms by the portion of stock held by individual investors directly or through mutual funds. Panel B splits the sample of firms by the portion of stock held directly by individual investors. In the second part of each panel, we report the coefficients on Basis-Price Ratio $_{t-1}$ in regressions that replace Tax Basis Pa-1 $_{t}$ and Stock Price $_{t-1}$ by their ratio. (Since the holdings data only starts in the first quarter of 1980 , we have to restrict the IPO sample.)

[Insert Table 9 Here]

The general pattern, which is robust across specification, is that the coefficient on the tax basis is large and significant for firms held by individuals but small and insignificant for firms held by institutions. This suggests that the tax basis is (not) a determinant of $\operatorname{tax}($ in) sensitive firms.

\subsection{Do personal taxes affect external financing?}

In addition to its implications for corporate investment, the model also has implications for external financing and the firm's equity-debt mix. The main prediction of the model for corporate financing is that firms owned by investors with low basis use more equity financing to fund investment than high-basis firms. We test this hypothesis using similar difference-in-difference techniques as in the previous section. 
The basic regression we run is of the following form:

$$
\begin{aligned}
& Y_{t}=c_{0}+c_{1} \text { Tax Basis } / O_{t-1}+c_{2} \text { Stock Price } / O_{t-1}+c_{3} M / B_{t-1} \\
& +c_{4} M / B_{t-1}^{e f w a}+c_{5} C F_{t-1}+c_{6} \text { Tangibility }_{t-1}+c_{7} \text { Size }_{t-1} \\
& \quad+c_{8} \text { Profitability } \text { fr }_{t-1}+c_{9} R \& D_{t-1}+c_{10} R D D_{t-1}+\epsilon_{t} .
\end{aligned}
$$

In this specification, the dependent variable $Y_{t}$ is equal to the change in book equity net of the change in retained earnings during the financial year $t-1$ through $t$ divided by year-end assets in the IPO year, denoted Equity Issuance . We expect the coefficient on the tax basis to be negative. In the robustness checks (Panel $\mathrm{C}$ ), we use an alternative dependent variable, Equity-Debt Mix $x_{t}$, which is defined as the portion of external funds raised in the form of equity during the financial year.

\section{[Insert Table 10 Here]}

Table 10 summarizes the results. The regressions are estimated with firm fixed effects (similar results are obtained in the robustness checks that use random effects). Standard errors are robust to clustering at the industry level defined by three-digit SIC codes and reported in parentheses. The significant negative coefficients on shareholders' tax basis support the hypothesis that low basis firms issue more equity than high basis firms. In Panel B, we report the corresponding coefficients when we replace Tax Basis $s_{t-1}$ and Stock Price t-1 $_{-1}$ by their ratio Basis-Price Ratiot-1, with same interpretation. In

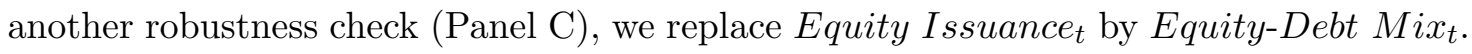
The negative coefficient we obtain implies that low basis firms tilt their financing mix towards equity, consistent with the predictions of the model.

\section{[Insert Table 11 Here]}

As in the analysis of investment, we expect the magnitude and significance of the coefficient $c_{1}$ on the tax basis to drop in financing regressions when we restrict the sample to tax insensitive firms. Table 11 reports the results when we estimate the financing regression separately for firms owned predominantly by individual investors or institutional investors, respectively. For this purpose we again split the sample into firms with $80 \%$ or more, $50 \%-80 \%$, and less than 50\% individual ownership. Each column corresponds to 
an ownership cluster. In Panel A, we split the sample using total individual ownership. In Panel B, we split the sample using direct individual ownership. The general pattern is that the coefficient on the tax basis is large and significant for firms held by individuals but small and insignificant for firms held by institutions. This result is robust to the basis proxy employed to conduct the analysis. The evidence suggests that a drop in tax basis leads to more equity financing only for firms owned by tax sensitive investors.

\subsection{Managerial shareholdings and firms' policy choices}

To make the analysis complete, this section examines whether the tax basis of management has an effect on firms' investment and financing decisions. To do so, we repeat the analysis conducted above for corporate investment, equity issuance, and the portion of external funds raised in the form of equity using management's tax basis, lagged one year, as explanatory variable.

We use two different methods to compute management's tax basis. First, we compute the ownership-weighted average basis of all insiders that are required to file SEC form 3,4 , and 5 when they trade in their companies' stock - management's basis proxy I. The types of insiders we include (based on the TFN insider role code) are CEO, CFO, COO, chairman of the board $(\mathrm{CB})$, officer $(\mathrm{O})$, director $(\mathrm{D})$, and president $(\mathrm{P})$. Second, we compute the ownership-weighted average basis of the CEO, CFO, and chairman of the board (CB) - management's basis proxy II.

In computing holdings, we follow Thomson Reuter's instructions and take the direct holdings with the highest sequence number on a document control number. We also exclude duplicate records and any records with cleanse code ' $A$ ' or ' $S$ ' for quality issues. Since the Thomson data on holdings is difficult to reconcile with the data on individual transactions, we use for consistency the holdings data to compute both the ownership share and the evolution of the insiders' average tax basis. We use the Thomson transactions data, augmented by CRSP stock price data, to determine the transaction date and price of insiders' stock purchases (and sales).

Based on the history of holdings, we compute each insider's tax basis as follows. The initial tax basis equals the stock price at the date the initial holdings are reported on Form 
3 or, if that is missing, the date of the first transaction. If the insider reduces his ownership share in a given period, the basis of the remaining shares (being the relevant forward looking quantity) equals the basis of the retained shares, that is Basist $=$ Basis $_{t-1}$. By contrast, if the insider is a net buyer of shares, we compute the new tax basis as the weighted-average of the basis on the old shares and the purchase price of the new shares: Basis $_{t}=P_{t} * w_{t}+$ Basis $_{t-1} *\left(1-w_{t}\right)$, where $w_{t}=$ Net purchases $t$ Shares held ${ }_{t}{ }^{15}$

According to the model, investment should be positively related and equity financing should be negatively related to management's tax basis (see section 4.5). We test these hypotheses using similar difference-in-difference techniques as in the previous section. The basic regression we run is of the following form:

$$
\begin{aligned}
Y_{t}=c_{0}+c_{1} \text { Management Basis } / O_{t-1}+c_{2} \text { Price } / O_{t-1}+c_{3} M / B_{t-1} \\
+c_{4} M / B_{t-1}^{\text {efwa }}+c_{5} C F_{t-1}+c_{6} \text { Tangibility }_{t-1}+c_{7} \text { Size }_{t-1} \\
\quad+c_{8} \text { Profitability }{ }_{t-1}+c_{9} R \& D_{t-1}+c_{10} R D D_{t-1}+c_{11} B D_{t-1}+\epsilon_{t} .
\end{aligned}
$$

In this specification, the variable $Y_{t}$ is equal to Investment $_{t}$, to Equity Issuance $_{t}$, or to Equity-Debt Mix , where these quantities are defined as above. The model is estimated with dummy variables for missing information on management's stock holdings, $B D_{t-1}$, since a sizeable fraction of ownership data is missing. In the first regression, we expect the coefficient on management's tax basis to be positive. In the other two regressions, we expect the coefficient on the tax basis to be negative.

\section{[Insert Table 12 Here]}

Table 12 summarizes the results (the coefficients on the constant and on the dummy variables for missing data are not reported). Standard errors are robust to clustering at the industry level defined by three-digit SIC codes and reported in parentheses. The

\footnotetext{
${ }^{15}$ The weighted-average method ignores tax incentives to sell securities from tax lots with the highest basis first (called "Highest In, First Out," or HIFO method). While the Internal Revenue Service does not recognize HIFO as an accounting method, it recognizes specific-shares accounting for reporting investment gains. According to IRS rules, if an investor does not indicate specific shares to sell, all gains and losses calculations automatically default to the "First In, First Out" method, meaning oldest purchases are sold first. Investment banks, however, often advise clients to sell securities using specific-share accounting with the HIFO method to lower capital gains taxes (and provide brokerage tools that assist with tracking).
} 
regressions in Panel A are estimated with firm fixed effects. The positive coefficient on management's tax basis in the first regression supports the hypothesis that low basis firms underinvest relative to high-basis firms. Similarly, the negative coefficient on management's tax basis in the other two regressions supports the hypothesis that low basis firms issue more equity than high basis firms and tilt their financing mix towards equity. In panel $\mathrm{B}$, we estimate the regressions using fixed effects and instrumental variables or with random effects. The coefficient $c_{1}$ is again positive and significant in the first regression and negative and significant in the other two regressions. Overall, the results using management's tax basis are consistent with the findings using individual ownership.

\section{Conclusion}

This paper shows that personal taxes can cause large distortions in corporate capital budgeting decisions. Specifically, we show that the hedge provided by capital loss offsets diminishes the option value of waiting to invest so that firms controlled by taxable investors speed up investment. We also show that capital gains taxes drive a wedge between the private valuations of the firm's incumbent owners and the market price and, as a result, distort financing choices. In particular, the analysis in the paper reveals that firms controlled by taxable investors employ more equity financing, the higher the firm's stock price and the lower the owners' basis, i.e., the larger the stock price-to-basis ratio.

The paper also provides supportive evidence for the predictions of the model using a broad sample of US industrial firms that are owned by taxable investors. Specifically, we find that our various proxies for investors' tax basis have economically and statistically significant explanatory power for corporate investment and financing in the way predicted by the model. Low basis firms invest less than high basis firms, controlling for various firm characteristics known to affect corporate financial policy. Low basis firms also raise more equity than high basis firms and shift their financing mix towards equity. We then show that the same tax measures that predict policy choices for firms held by individuals do not predict investment and financing choices for firms held by institutions. 


\section{Appendix}

\section{A Proof of proposition 1}

Constantinides (1983, Theorem 1) provides the proof in the case with no leverage. Consider the case with leverage. The optimality conditions for selling a share with basis $B \geq 0$ at cash-flow trigger $b(m ; B)$ and, respectively, for defaulting at $l(m)$ when the decision maker's basis is $B \geq 0$ are

$$
\begin{aligned}
v_{x}(b(m ; B) ; B) & =(1-\tau) p_{x}(b(m ; B)) \quad(\geq 0), \\
v_{x}(l(m) ; B) & =0 .
\end{aligned}
$$

Absence of arbitrage requires $p_{x}(x) \geq 0$ for all feasible $x$, so the right-hand side of equation (A.1) is positive. The left-hand side, $v_{x}(x ; B)$, is continuous in $x$, and the process $X=$ $\left(X_{t}\right)_{t \geq 0}$ has continuous sample paths. Hence, condition (A.1) yields $b\left(m ; B_{1}\right) \leq b\left(m ; B_{2}\right)$ for $B_{1} \leq B_{2}$, and the comparison with equation (A.2) yields $l(m) \leq b(m ; B)$ for all $B \geq 0$. This shows that shareholders optimally reset their tax basis before declaring bankruptcy, or in terms of the trigger policies:

$$
l(m)=b(m ; 0) \leq b(m ; B) \text { for all } B \geq 0 \text { and } m \in \mathcal{M} .
$$

\section{B Proof of propositions 2 and 3}

Take as given the firm's policy functions, $\left(u(m), c^{1}(m), n^{1}(m), l^{0}(m), l^{1}(m)\right)$, and drop the dependence of $m$ where obvious.

Private equity valuation $v^{1}(x, m ; B)$ : The solution to equations $(7,8)$ is standard. See, e.g., Dixit and Pindyck (1994, Investment under Uncertainty, Princeton University Press).

Stock price $p^{1}(x, m)$ : The stock price $p^{1}(x, m)$ is given implicitly as the fixed-point to equation (4). To determine the stock price explicitly we use condition (3) and the optimality conditions (8) for tax-loss selling and for default. Conditions (8) hold for arbitrary $B \geq 0$ and so for arbitrary $b^{1}(m ; B) \geq l^{1}(m)$, since by equation (3) there is a one-to-one mapping between $B$ and $b^{1}(m ; B)$. Rearranging terms, $p^{1}(x, m)$ solves the following first-order differential equation in terms of $x$ given $l^{1}(m)$ for all $m \in M$ :

$p_{x}^{1}(x, m)=\frac{1}{1-\tau} v_{x}^{1}\left(x, m ; p^{1}(x, m)\right)$ for $x>l^{1}(m), \quad p^{1}\left(l^{1}(m), m\right)=0, \quad p_{x}^{1}\left(l^{1}(m), m\right)=0$.

The solution to equation (B.1) is given by equation (17). 
Default Trigger $l^{1}(m)$ : Using equation (15), we have $v_{x}^{1}(x, m ; 0)=\frac{\lambda}{n^{1}}\left[1+\gamma\left(\frac{l^{1}}{x}\right)^{\gamma}\left(\frac{\lambda l^{1}-\delta c^{1}}{\lambda x}\right)\right]$. The smooth-pasting condition $v_{x}^{1}\left(l^{1}(m), m ; 0\right)=0$ then yields the trigger (18).

Debt value $D^{1}(x, m)$ : Debtholders in aggregate receive after-tax coupon flows $c^{1}(1-$ $\tau^{p}$ ) while the firm is solvent and $1-\alpha$ per cent of the value of the unlevered assets, $\beta \lambda x$, when the firm enters default (as in Leland, 1994). Holders of risky debt can also claim capital loss offsets (in the same way as equityholders). The private debt valuation given basis $D$ is thus $D^{1}(x, m ; D)=\frac{1-\tau^{p}}{r} c^{1}+\left(\frac{d^{1}(m ; D)}{x}\right)^{\gamma}\left[D-\frac{1-\tau^{p}}{r} c^{1}\right]$, where $d^{1}(m ; D)$ is the basis-reset trigger. The market price $D^{1}(x, m)$ satisfies a differential equation similar to equation (B.1):

$$
\begin{aligned}
D_{x}^{1}(x, m) & =\frac{1}{1-\tau} D_{x}^{1}\left(x, m ; D^{1}(x, m)\right) \text { for } x>l^{1}(m), \\
D^{1}\left(l^{1}(m), m\right) & =(1-\alpha) V^{*}\left(l^{1}(m)\right), \quad \lim _{x \rightarrow \infty} D^{1}(x, m)=\frac{c^{1}\left(1-\tau^{p}\right)}{r} .
\end{aligned}
$$

The last condition in equation (B.2) requires that debt becomes riskless as $x \rightarrow \infty$. Since all debt issues, by assumption, have the same priority and recovery rate in the event of bankruptcy, it is sufficient to value the aggregate debt. The solution to equation (B.2) is equation (19).

Optimal static leverage ratio: The market value of the unlevered firm $V^{*}$ in equation (B.2) takes the simple form $V^{*}(x)=\beta \lambda x$ with $\beta=(1+\gamma) /(1+\gamma-\tau)$, as shown by Constantinides (1983, footnote 6$)$. The solution to equation (B.2) is $D^{1}(x, m)=$ $\frac{1-\tau^{p}}{r} c^{1}+\left(\frac{l^{1}}{x}\right)^{\frac{\gamma}{1-\tau}}\left[(1-\alpha) V^{*}\left(l^{1}\right)-\frac{1-\tau^{p}}{r} c^{1}\right]=\frac{1-\tau^{p}}{r} c^{1}\left[1-\omega\left(\frac{l^{1}}{x}\right)^{\frac{\gamma}{1-\tau}}\right]$, where the total bankruptcy cost $\omega$ is defined by

$$
\omega=1-\frac{1-\tau^{e}}{1-\tau^{p}} \frac{\gamma(1-\alpha)}{1+\gamma-\tau}
$$

The market value of an optimally capitalized firm (with endogenous basis) is $p^{*}(x, x)+$ $D^{*}(x, x)$ with functional forms for $p^{*}$ and $D^{*}$ given by equations $(17,19)$. This expression is maximized for a coupon flow of $c^{*}(x)=\vartheta \frac{1+\gamma}{\gamma} \frac{\lambda}{\delta} x$ with constant $\vartheta$ defined by expression (27). The optimal static leverage ratio, $\frac{D^{*}(x, x)}{p^{*}(x, x)+D^{*}(x, x)}$, is then given by expression $(26)$.

Valuation of Equity and Debt Claims Before Investment: Valuations before investment depend on both the investor's own basis $B \in B^{0}(m)$ and the basis of the managerial decision maker, $p^{0}(m, m)$. The latter determines the optimal investment trigger $u(m)$ and the financing mix $\left(c^{1}(m), n^{1}(m)\right)$. In period 0 the set of feasible tax bases is $B^{0}(m)=\left\{B: p^{0}(m, m) \leq B \leq \sup _{x \geq m} p^{0}(u(x), x)\right\}, m \in M$ (there exist no shares with $\left.B<p^{0}(m, m)\right)$. 
Private equity valuation $v^{0}(x, m ; B)$ : The solution to equations $(9,10)$ is standard. Shareholders receive pre-tax cash flows $\pi X_{t}-c^{0}$ while the firm takes no action (default or restructuring). Once operating income $X_{t}$ falls to $b^{0}\left(M_{t} ; B\right)$, shareholders sell all shares with basis $B$ and receive after-tax proceeds per share of $(1-\tau) p^{0}\left(b^{0}\left(M_{t} ; B\right), M_{t}\right)+\tau B$. When the firm exercises its real option, equity is worth $v^{1}\left(u\left(M_{t}\right), M_{t} ; B\right)$. Let $\varphi_{b}^{0}(x, m ; B)$ and $\varphi_{u}^{0}(x, m ; B)$ be state-contingent claims that pay either a single unit when $X_{t}$ hits the basis-reset threshold $b^{0}\left(M_{t} ; B\right)$ before the investment boundary $u\left(M_{t}\right)$ (subscript $b$ ) or vice versa (subscript $u$ ). The solutions to $\varphi_{b}^{0}$ and $\varphi_{u}^{0}$ are standard. Let $\varphi_{b}^{1}(x, m ; B)=$ $\left(\frac{b^{1}(m ; B)}{x}\right)^{\gamma}$ and $\varphi_{l}^{1}(x, m)=\left(\frac{l^{1}(m)}{x}\right)^{\gamma}$ be state-contingent claims that pay either a single unit when $X_{t}$ hits the basis-reset threshold $b^{1}(m ; B)$ or the default threshold $l^{1}(m)$, respectively.

Stock price $p^{0}(x, m)$ : The stock price before investment, $p^{0}(x, m)$, can again be determined using the optimality conditions for tax-loss selling, much like in equation (B.1). In case $x>m$, the optimality conditions for an investor with basis $B>p^{0}(m, m)$ are identical to those in equation (8). As a result, $m$ can be treated as a parameter, which yields equation (B.4). In case $x=m$, the relevant optimality conditions are the ones of the managerial decision maker who must take into consideration that the firm's policy depends on her tax timing decision (the state variable $m$ is a decision variable in the tax timing problem, and only at the optimum it coincides with the running minimum of $X$ ). Let $p^{0}(x) \equiv p^{0}(x, x)$. The optimality conditions are as follows in case $x=m$ :

$$
\begin{array}{ll}
\text { Tax-Loss Selling: } & v^{0}\left(m, m ; p^{0}(m)\right)=p^{0}(m), \\
& v_{x}^{0}\left(m, m ; p^{0}(m)\right)=(1-\tau) p_{x}^{0}(m) . \\
& v^{0}\left(l^{0}, l^{0} ; 0\right)=p^{0}\left(l^{0}\right)=0, \\
\text { Default: } & v_{x}^{0}\left(l^{0}, l^{0} ; 0\right)=p_{x}^{0}\left(l^{0}\right)=0 .
\end{array}
$$

In the set $\{(x, m): x=m\}$ there exists a one-to-one mapping between tax-loss selling trigger $b$ and tax basis $B$. One obtains the following free-boundary problem for $l^{0}$, $p^{0}(x, m)$, and $p^{0}(x)$ :

$$
\begin{aligned}
p_{x}^{0}(x, m) & =\frac{1}{1-\tau} v_{x}^{0}\left(x, m ; p^{0}(x, m)\right) \text { for } m<x<u(m), \\
p^{0}(x, m) & =p^{1}(x, m) \text { for } x=u(m), \\
p^{0}(x, m) & =p^{0}(m) \text { for } x=m . \\
p_{x}^{0}(x) & =\frac{1}{1-\tau} v_{x}^{0}\left(x, x ; p^{0}(x)\right) \text { for } l^{0}<x<u(x), \\
p^{0}(x) & =p^{1}(x, x) \text { for } x=u(x), \\
p^{0}(x) & =0 \text { and } p_{x}^{0}(x)=0 \text { for } x=l^{0} .
\end{aligned}
$$


The solution to equations (B.4, B.5) is a second-order Volterra integral equation for $p^{0}(x, m)$ that can be reduced to the following first-order integral equation:

$$
\begin{aligned}
p^{0}(x, m) & =f(x, m) p^{0}(m)+\frac{1}{1-\tau} \int_{m}^{x} g(x, m, z) d z, m \leq x \leq u(m), \\
p^{0}(x) & \equiv p^{0}(x, x)=\frac{1}{1-\tau} \int_{l^{0}}^{x} h(x, z) d z, l^{0} \leq x \leq u(x),
\end{aligned}
$$

where

$$
\begin{aligned}
f(x, m) & \equiv e^{\frac{1}{1-\tau} \int_{m}^{x} \Phi_{u}(s, m) \Psi_{1}(s, m) d s} \Psi_{0}(x, m, m), \\
g(x, m, z) & \equiv e^{\frac{1}{1-\tau} \int_{z}^{x} \Phi_{u}(s, m) \Psi_{1}(s, m) d s} \Psi_{0}(x, m, z) \Psi_{2}(z, m), \\
h(x, z) & \equiv e^{\frac{1}{1-\tau} \int_{z}^{x}\left(\Phi_{b}(s, s)+\Phi_{u}(s, s) \Psi_{1}(s, s)\right) d s} \Psi_{2}(z, z) .
\end{aligned}
$$

Let $\mathbf{x} \equiv x / u(m)$. The functions $\Phi_{b}(x, m), \Phi_{u}(x, m), \Psi_{0}(x, m, z), \Psi_{1}(x, m), \Psi_{2}(x, m)$ equal

$$
\begin{aligned}
\Phi_{b}(x, m) & \equiv \frac{\partial \varphi_{b}^{0}\left(x, m ; p^{0}(x, m)\right)}{\partial x}=\frac{\eta \mathbf{x}^{\gamma}-\gamma \mathbf{x}^{\eta}}{\mathbf{x}^{\eta}-\mathbf{x}^{\gamma}} x^{-1}, \\
\Phi_{u}(x, m) & \equiv \frac{\partial \varphi_{u}^{0}\left(x, m ; p^{0}(x, m)\right)}{\partial x}=\frac{\gamma-\eta}{\mathbf{x}^{\eta}-\mathbf{x}^{\gamma}} x^{-1}, \\
\Psi_{0}(x, m, z) & \equiv e^{\frac{1}{1-\tau} \int_{z}^{x} \Phi_{b}(s, m) d s}=\varphi_{b}^{0}\left(x, m ; p^{0}(z, m)\right)^{\frac{1}{1-\tau}}=\left[\frac{\mathbf{x}^{\eta}-\mathbf{x}^{\gamma}}{(x / z)^{\gamma} \mathbf{x}^{\eta}-\mathbf{x}^{\gamma}(x / z)^{\eta}}\right]^{\frac{1}{1-\tau}}, \\
\Psi_{1}(x, m) \equiv & \varphi_{b}^{1}\left(u(m), m ; p^{0}(x, m)\right), \\
\Psi_{2}(x, m) \equiv & \left\{\pi \lambda-\Phi_{b}(x, m)\left(\pi \lambda x-\delta c^{0}\right)+\Phi_{u}(x, m)\left[\left(1 / n^{1}-\pi\right) \lambda u(m)\right.\right. \\
& \left.\left.\quad-\delta\left(c^{1} / n^{1}-c^{0}\right)-\Psi_{1}(x, m)\left(\lambda b^{1}(x, m)-\delta c^{1}\right) / n^{1}\right]\right\},
\end{aligned}
$$

where $b^{1}(x, m) \equiv b^{1}\left(m ; p^{0}(x, m)\right)$ determines how the tax timing thresholds shift after investment.

\section{Value-maximizing investment and financing policies}

Apply backward induction as follows: First, solve for the optimal financing mix, $c^{1}=$ $c^{1}(u(m), m)$ and $n^{1}=n^{1}(u(m), m)$, taking $m$ and $u(m)$ as given. Then, determine the investment trigger $u(m)$ for each $m \in M$ while imposing the optimal financing and optimal bankruptcy policies.

Budget constraint. The budget constraint (6) can be expressed in terms of $\left(c^{1}, n^{1}\right)$ as

$$
E^{1}\left(u(m), m \mid c^{1}\right)\left(1-\frac{1}{n^{1}}\right)+\Delta D\left(u(m), m \mid c^{1}\right)-I=0,
$$


where $E^{1}(x, m)$ denotes the market value of the firm's equity:

$$
E^{1}\left(x, m \mid c^{1}\right)=\beta \lambda x-\delta c^{1}-\left(\frac{l^{1}(m)}{x}\right)^{\frac{\gamma}{1-\tau}}\left(\beta \lambda l^{1}(m)-\delta c^{1}\right) .
$$

The Implicit Function Theorem guarantees the existence of a differentiable policy function $n^{1}\left(x, m \mid c^{1}\right)$, linking the total debt coupon to the size of the equity offering. One obtains

$$
\begin{aligned}
\frac{\partial}{\partial c^{1}} n^{1}\left(x, m \mid c^{1}\right)^{-1} & =\frac{1}{E^{1}}\left[\frac{\partial E^{1}\left(x, m \mid c^{1}\right)}{\partial c^{1}}\left(1-\frac{1}{n^{1}}\right)+\frac{\partial \Delta D\left(x, m \mid c^{1}\right)}{\partial c^{1}}\right] \\
\frac{\partial}{\partial x} n^{1}\left(x, m \mid c^{1}\right)^{-1} & =\frac{1}{E^{1}}\left[\frac{\partial E^{1}\left(x, m \mid c^{1}\right)}{\partial x}\left(1-\frac{1}{n^{1}}\right)+\frac{\partial \Delta D\left(x, m \mid c^{1}\right)}{\partial x}\right]
\end{aligned}
$$

with

$$
\begin{aligned}
\frac{\partial}{\partial c^{1}} E^{1}\left(x, m \mid c^{1}\right) & =-\delta\left[1-\varphi_{l}^{1}\left(x, m \mid c^{1}\right)^{\frac{1}{1-\tau}}\right] \\
\frac{\partial}{\partial c^{1}} \Delta D\left(x, m \mid c^{1}\right) & =\frac{1-\tau^{p}}{r}\left\{1-\alpha \varphi_{l}^{1}\left(x, m \mid c^{1}\right)^{\frac{1}{1-\tau}}\left[1+\frac{\gamma}{1-\tau}\left(1-\frac{c^{0}}{c^{1}}\right)\right]\right\}, \\
\frac{\partial}{\partial x} E^{1}\left(x, m \mid c^{1}\right) & =\left[\beta \lambda x+\frac{\gamma}{1-\tau} \varphi_{l}^{1}\left(x, m \mid c^{1}\right)^{\frac{1}{1-\tau}}\left(\beta \lambda l^{1}-\delta c^{1}\right)\right] \frac{1}{x}, \\
\frac{\partial}{\partial x} \Delta D\left(x, m \mid c^{1}\right) & =\frac{\gamma}{1-\tau} \alpha \varphi_{l}^{1}\left(x, m \mid c^{1}\right)^{\frac{1}{1-\tau}} \frac{1-\tau^{p}}{r}\left(\frac{c^{1}-c^{0}}{x}\right) .
\end{aligned}
$$

In equations (C.3, C.4) we have used that the optimal bankruptcy trigger $l^{1}=l^{1}\left(c^{1}\right)$ is affine in $c^{1}$, and $\frac{\partial}{\partial l^{1}} E^{1}\left(x, m \mid c^{1}\right)=0$ by optimality of $l^{1}$

Optimal financing. Denote by $c^{1}(x, m)$ and $n^{1}\left(x, m \mid c^{1}\right)$ the financing policy given $(x, m)$. Optimal financing at $x=u(m)$ requires the following necessary and sufficient first-order condition to hold for $c^{1} \geq 0$ :

$$
\frac{\partial}{\partial c^{1}} v^{1}\left(u(m), m ; p^{0}(m, m) \mid c^{1}, n^{1}\left(u(m), m \mid c^{1}\right)\right)=0,
$$

where

$$
\begin{gathered}
\frac{\partial}{\partial c^{1}} v^{1}\left(x, m ; B \mid c^{1}, n^{1}\left(x, m \mid c^{1}\right)\right)=\left(\lambda x-\delta c^{1}\right) \frac{\partial n^{1}\left(x, m \mid c^{1}\right)^{-1}}{\partial c^{1}}-\frac{\delta}{n^{1}}+\varphi_{b}^{1}(x, m ; B) \\
\times\left[(1-\tau) \frac{\partial p^{1}\left(b^{1}, m \mid c^{1}, n^{1}\right)}{\partial c^{1}}-\left(\lambda b^{1}-\delta c^{1}\right) \frac{\partial n^{1}\left(x, m \mid c^{1}\right)^{-1}}{\partial c^{1}}+\frac{\delta}{n^{1}}\right],
\end{gathered}
$$

In (C.6) we have used that $\frac{\partial}{\partial b^{1}} v^{1}\left(x, m ; B \mid c^{1}, n^{1}\right)=\frac{\partial}{\partial l^{1}} v^{1}\left(x, m ; B \mid c^{1}, n^{1}\right)=0$, by optimality of $l^{1}$ and $b^{1}$. The solution to equation (C.5) is a policy function $m \mapsto c^{1}(m)$ for $m \in M$. 
Investment threshold. Take $c^{1}(x, m)$ and $n^{1}\left(x, m \mid c^{1}\right)$ as given. Given $m$, optimality of $u(m)$ requires the following value-matching and smooth-pasting conditions to be satisfied at $x=u(m)$ :

$$
\begin{aligned}
v^{0}\left(x, m ; p^{0}(m, m)\right) & =v^{1}\left(x, m ; p^{0}(m, m) \mid c^{1}(x, m), n^{1}\left(x, m \mid c^{1}\right)\right), \\
\frac{\partial}{\partial x} v^{0}\left(x, m ; p^{0}(m, m)\right) & =\frac{\partial}{\partial x} v^{1}\left(x, m ; p^{0}(m, m) \mid c^{1}(x, m), n^{1}\left(x, m \mid c^{1}\right)\right) .
\end{aligned}
$$

The right-hand side and the left-hand side of equation (C.9), respectively, equal

$$
\begin{aligned}
& \frac{\partial}{\partial x} v^{1}(\cdot)=\left(\lambda x-\delta c^{1}\right) \frac{\partial n^{1}\left(x, m \mid c^{1}\right)^{-1}}{\partial x}+\frac{\lambda}{n^{1}}+\varphi_{b}^{1}(x, m ; B) \\
& \times\left\{\left[(1-\tau) n^{1} B-\left(\lambda b^{1}-\delta c^{1}\right)\right] \frac{\partial n^{1}\left(x, m \mid c^{1}\right)^{-1}}{\partial x}-\gamma \frac{1}{x}\left(B-\frac{\lambda b^{1}-\delta c^{1}}{n^{1}}\right)\right\} \\
& \frac{\partial}{\partial x} v^{0}(\cdot)=\pi \lambda+\frac{\partial}{\partial x} \varphi_{b}^{0}(x, m ; B)\left[B-\left(\pi \lambda b^{0}(m ; B)-\delta c^{0}\right)\right] \\
&+\frac{\partial}{\partial x} \varphi_{u}^{0}(x, m ; B)\left[v^{1}(u(m), m ; B)-\left(\pi \lambda u(m)-\delta c^{0}\right)\right]
\end{aligned}
$$

since $\frac{\partial}{\partial x} p^{1}\left(b^{1}, m \mid c^{1}(x, m), n^{1}\left(x, m \mid c^{1}\right)\right)=n^{1} B \frac{\partial}{\partial x} n^{1}\left(x, m \mid c^{1}\right)^{-1}$. In equation (C.10), $b^{1}=$ $b^{1}(m ; B)$ and $c^{1}$ can be treated as constants since optimal financing requires $\frac{\partial}{\partial c^{1}} v^{1}(x, m ; B \mid$ $\left.c^{1}, n^{1}\left(x, m \mid c^{1}\right)\right)=0$.

\section{Proof of proposition 4}

The firm's financial policy can be characterized by a policy function $c^{1}(x, m \mid B)$, representing the total promised debt coupon flow after investment given the owners' basis $B$ (the budget constraint (C.1) yields the number of shares outstanding after investment, $\left.n^{1}(x, m \mid B)\right)$. The claim

$$
\frac{\partial}{\partial B} c^{1}(x, m \mid B)=\frac{\frac{\partial^{2} v^{1}\left(x, m ; B \mid c^{1}, b^{1}\right)}{\partial c^{1} \partial b^{1}} \frac{\partial b^{1}(m ; B)}{\partial B}+\frac{\partial^{2} v^{1}\left(x, m ; B \mid c^{1}\right)}{\partial c^{1} \partial B}}{-\frac{\partial^{2} v^{1}\left(x, m ; B \mid c^{1}\right)}{\left(\partial c^{1}\right)^{2}}} \geq 0
$$

requires the numerator in equation (D.1) to be positive, since the second-order optimality condition for $c^{1}(x, m \mid B)$ yields that the denominator in (D.1) is positive. After some algebra the numerator in equation (D.1) equals

$$
(-\tau) \frac{\gamma}{b^{1}(m ; B)} \varphi_{b}^{1}\left(x, m ; B \mid c^{1}\right) \frac{\partial p^{1}\left(b^{1}(m ; B), m \mid c^{1}\right) / \partial c^{1}}{\partial p^{1}\left(b^{1}(m ; B), m\right) / \partial b^{1}} .
$$

By the Implicit Function Theorem and the property $\frac{\partial}{\partial x} p^{1}(x, m) \geq 0$ for all $x \geq m$,

$$
\frac{\partial p^{1}\left(b^{1}(m ; B), m\right)}{\partial b^{1}}=\left(\frac{\partial b^{1}(m ; B)}{\partial B}\right)^{-1} \geq 0 .
$$


So the claim (D.1) is verified if and only if at the optimal financing mix,

$$
\left.\frac{\partial p^{1}\left(b^{1}(m ; B), m \mid c^{1}\right)}{\partial c^{1}}\right|_{c^{1}=c^{1}(x, m \mid B)} \leq 0,
$$

Using equations (C.3, C.7),

$$
\begin{aligned}
& \left.\frac{\partial p^{1}\left(b^{1}(m ; B), m \mid c^{1}\right)}{\partial c^{1}}\right|_{c^{1}=c^{1}(x, m \mid B)} \\
& =\mathbf{I}\left(x, m ; B \mid c^{1}\right)\left\{\beta\left[b^{1}(m ; B)-\varphi_{l}^{1}\left(b^{1}(m ; B), m\right)^{\frac{1}{1-\tau}} l^{1}\right]\left[1-\varphi_{b}^{1}(u(m), m ; B)\right]\right. \\
& \left.-\left[u(m)-\varphi_{b}^{1}(u(m), m ; B) b^{1}(m ; B)\right]\left[1-\varphi_{l}^{1}\left(b^{1}(m ; B), m\right)^{\frac{1}{1-\tau}}\right]\right\}
\end{aligned}
$$

where

$\mathbf{I}\left(x, m ; B \mid c^{1}\right) \equiv \frac{\lambda \partial\left(1 / n^{1}\right) / \partial c^{1}}{1-\varphi_{b}^{1}(u(m), m ; B)+\varphi_{b}^{1}(u(m), m ; B)(1-\tau)\left[1-\varphi_{l}^{1}\left(b^{1}(m ; B), m\right)^{\frac{1}{1-\tau}}\right]} \geq 0$.

It remains to show that the term in equation (D.3) enclosed in curly brackets is negative. This amounts to an inequality of the form

$$
\beta \frac{1-\mathbf{z}^{1+\frac{\gamma}{1-\tau}}}{1-\mathbf{z}^{\frac{\gamma}{1-\tau}}} \leq \frac{1-\mathbf{x}^{1+\gamma}}{\mathbf{x}-\mathbf{x}^{1+\gamma}} \quad \text { for all } \mathbf{z}, \mathbf{x} \in(0,1)
$$

where $\mathbf{z} \equiv l^{1} / b^{1}(m ; B)$ and $\mathbf{x} \equiv b^{1}(m ; B) / u(m)$. By L'Hospital's rule, the l.h.s of equation (D.4) is monotonically increasing in $z$ on $(0,1)$ and bounded above by $1+\frac{1}{\gamma}$. The r.h.s of equation (D.4) is monotonically decreasing in $x$ and bounded below by $1+\frac{1}{\gamma}$. 


\section{References}

Ang, A., and G. Bekaert, 2002, "International Asset Allocation with Regime Shifts," Review of Financial Studies 15, 1137-1187.

Ayers, B., C. Lefanowicz, and J. Robinson, 2003, "Shareholder taxes in acquisition premiums: The effect of capital gains taxation," Journal of Finance 58, 2785-2803.

Baker, M. and J. Wurgler, 2002, "Market Timing and Capital Structure," Journal of Finance 57, 1-32.

Bayless, M. and S. Chaplinsky, 1996, "Is there a Window of Opportunity for Seasoned Equity Issuance?" Journal of Finance 51, 253-278.

Benninga, S., M. Helmantel and O. Sarig, 2005, "The Timing of Initial Public Offerings," Journal of Financial Economics 75, 115-132.

Bernanke, B.,1983, "Irreversibility, Uncertainty, and Cyclical Investment," Quarterly Journal of Economics 98, 85-106.

Constantinides, G., 1983, "Capital Market Equilibrium with Personal Tax," Econometrica 51, 611-636.

Dai, Z., E. Maydew, D. Shackelford, and H. Zhang, 2008, "Capital Gains Taxes and Asset Prices: Capitalization or Lock-in?" Journal of Finance 63, 709-742.

Fan, H. and S. Sundaresan, 2000, "Debt Valuation, Renegotiation, and Optimal Dividend Policy," Review of Financial Studies 13, 1057-1099.

Fazzari, S., R.G. Hubbard and B.C. Petersen, 1988, "Financing Constraints and Corporate Investment," Brookings Papers on Economic Activity 1, 141-195.

Feldstein, M., and L. Summers, 1979, "Inflation and Taxation of Capital Income in the Corporate Sector," National Tax Journal 41, 219-233.

Fischer, E., R. Heinkel and J. Zechner, 1989, "Optimal Dynamic Capital Structure Choice: Theory and Tests," Journal of Finance 44, 19-40.

Gordon, R., 1985, "Taxation of Corporate Capital Income: Tax Revenues Versus Tax Distortions," Quarterly Journal of Economics 100, 1-27.

Graham, J., 1999, "Do Personal Taxes Affect Corporate Financing Decisions?" Journal of Public Economics, 73 147-185. 
Graham, J., 2000, "How Big Are the Tax Benefits of Debt?" Journal of Finance 55, 1901-1941.

Green, R., and B. Hollifield, 2003, "The Personal Tax Advantages of Equity," Journal of Financial Economics 67, 175-216.

Green, R. and E. Talmor, 1985, "The Structure and Incentive Effects of Corporate Tax Liabilities," Journal of Finance 40, 1095-1114.

Grinblatt, M., and B. Han, 2005, "Prospect Theory, Mental Accounting, and Momentum," Journal of Financial Economics 78, 311-339.

Grinblatt, M. and M. Keloharju, 2000, "The Investment Behavior and Performance of Various Investor Types: A Study of Finland's Unique Data Set," Journal of Financial Economics 55, 43-67.

Hackbarth, D., J. Miao and E. Morellec, 2006, "Capital Structure, Credit Risk, and Macroeconomic Conditions," Journal of Financial Economics 82, 519-550.

Hennessy, C., and T. Whited, 2007, "How Costly is External Financing? Evidence from a Structural Estimation," Journal of Finance 62, 1705-1743.

Ivković, Z., J. Poterba and S. Weisbenner, 2005, "Tax-Motivated Trading by Individual Investors," American Economic Review 95, 1605-1630.

Jin, L., 2006, "Capital Gain Tax Overhang and Price Pressure," Journal of Finance 61, 1399-1431.

Kole, S., 1997, "The Complexity of Compensation Contracts," Journal of Financial Economics 43, 79-104.

Leary, M. and M. Roberts, 2005, "Do Firms Rebalance Their Capital Structures?" Journal of Finance, 60, 2575-2619.

Leland, H., 1994, "Corporate Debt Value, Bond Covenants, and Optimal Capital Structure," Journal of Finance 49, 1213-1252.

Leland H., 1998, "Agency Costs, Risk Management, and Capital Structure," Journal of Finance 53, 1213-1243.

Lewellen, J., and K. Lewellen, 2006, "Internal Equity, Taxes, and Capital Structure," Working Paper, Dartmouth College.

Liu, H., and M. Loewenstein, 2008, "Liquidity Premia and Transaction Costs," Forthcoming Journal of Finance. 
Lo, A., H. Mamaysky, and J. Wang, 2004, "Asset Prices and Trading Volume under Fixed Transaction Costs," Journal of Political Economy 112, 1054-1090.

Lobanov S., and I. Strebulaev, 2008, "A Theory of Dynamic Corporate Financing and Investment," Working Paper, Stanford University.

Masulis, R. and A. Korwar, 1986, "Seasoned Equity Offers: An Empirical Investigation," Journal of Financial Economics 15, 91-118.

Miller, M., 1977, "Debt and Taxes," Journal of Finance 32, 261-275.

Modigliani, F. and M. Miller, 1958, "The Cost of Capital, Corporation Finance and the Theory of Investment," American Economic Review 48, 261-297.

Morellec, E., 2004, "Can Managerial Discretion Explain Observed Leverage Ratios?" Review of Financial Studies 17, 257-294.

Petersen, M., 2008, "Estimating Standard Errors in Finance Panel Data Sets: Comparing Approaches," Forthcoming Review of Financial Studies.

Revuz, D., and M. Yor, 1999, Continuous Martingales and Brownian Motion, 3rd edition, Springer Verlag, Berlin.

Ross, S., 1987, "Arbitrage and Martingales with Taxation," Journal of Political Economy 95, 371-393.

Strebulaev, I., 2007, "Do Tests of Capital Structure Mean What They say?" Journal of Finance 62, 1747-1787.

Sundaresan, S., and N. Wang, 2006, "Dynamic Investment, Capital Structure, and Debt Overhang," Working Paper, Columbia University.

Welch, I., 2004, "Capital Structure and Stock Returns," Journal of Political Economy $112,106-131$.

Williams, J., 1985, "Trading and Valuing Depreciable Assets," Journal of Financial Economics 14, 283-308.

Zwiebel, J., 1996, "Dynamic Capital Structure under Managerial Entrechment," American Economic Review 86, 1197-1215. 


\section{Figure 1: State SpaCe of the Dynamic investment PRoblem.}

The state space of the dynamic investment problem can be partitioned into various domains including a default region $(\mathcal{L})$ where it is optimal for shareholders to default immediately, an investment region $(\mathcal{U})$ where it is optimal to invest, and an inaction or continuation region $(\mathcal{C})$. The arrows indicate the feasible direction of movement in the state space for the cases $x>m$ and $x=m$.

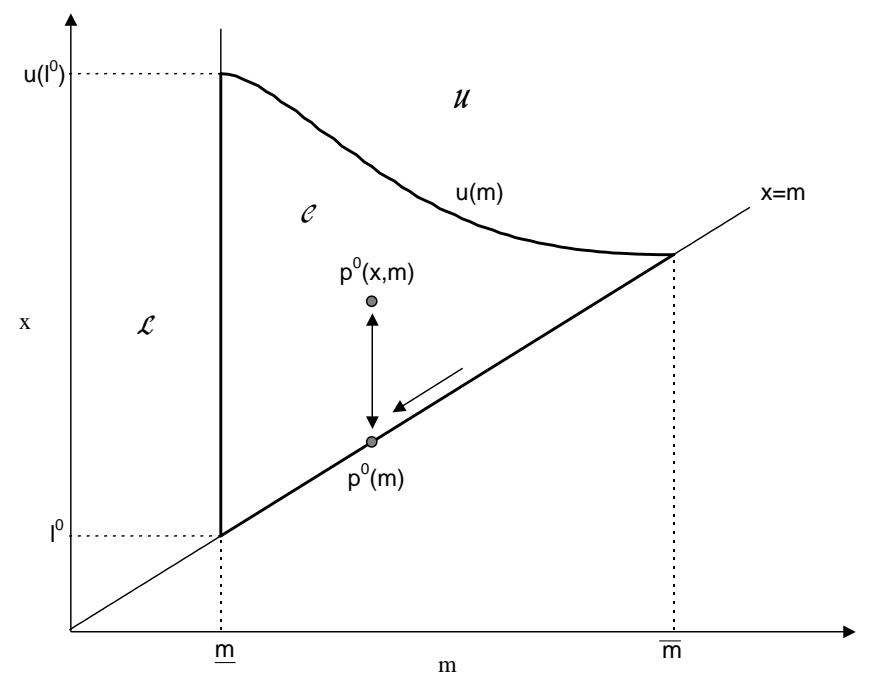

Figure 2: The timing of InVESTMENT.

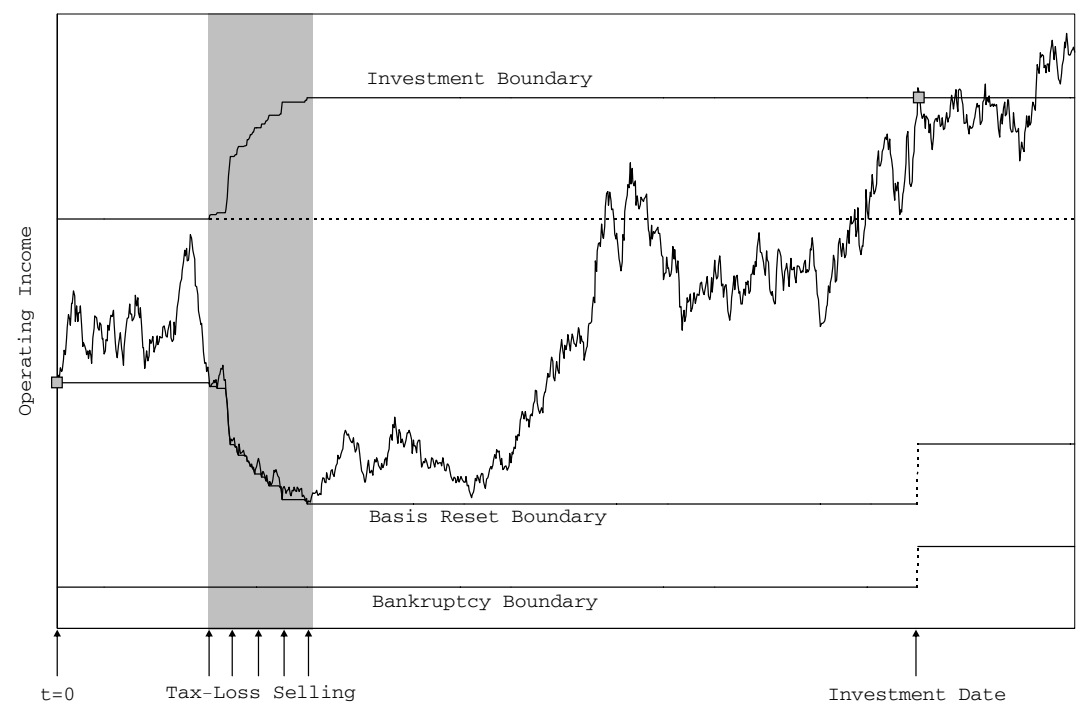


Figure 3: Comparative statics.

The figure plots the firm's investment boundary (left) and the target leverage ratio (right) for different values of the capital gains tax rate $\tau$. The line marked Basis $=0$ corresponds to a basis-price ratio of zero, and the line marked Basis = Price corresponds to a basis-price ratio of one at the investment date.
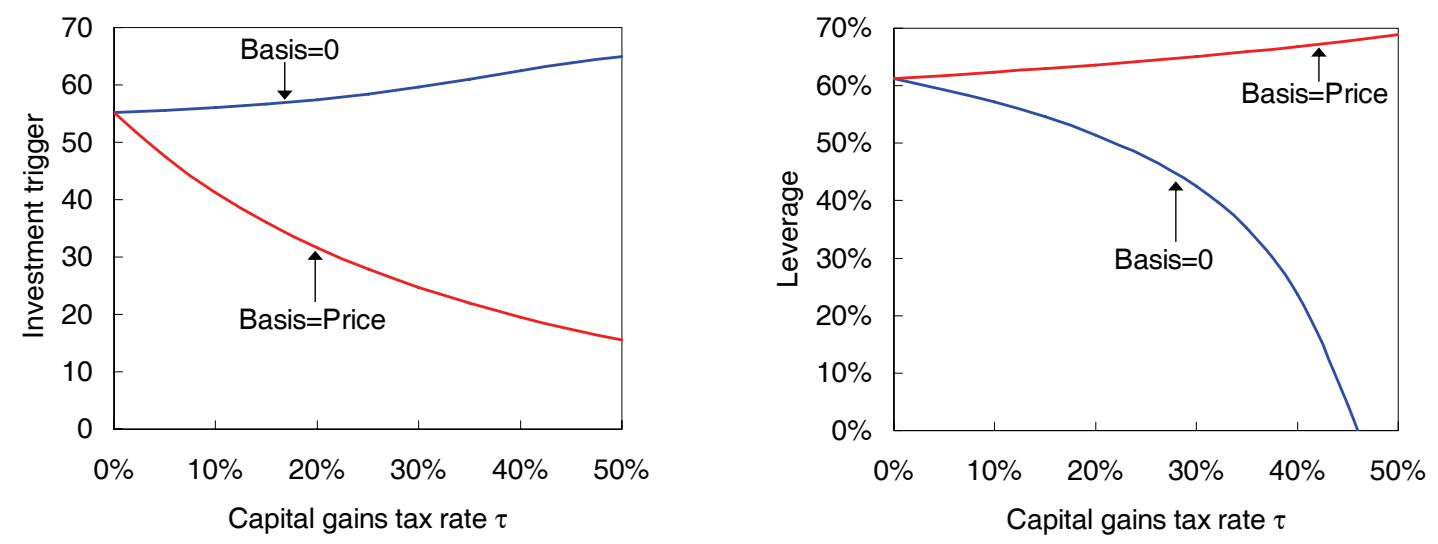

Figure 4: DEFAult BOUndary.

The different panels plot the default boundary before (solid) and after (dashed) exercise of the real option for different parameter values. The default boundary is expressed in terms of the interest coverage ratio at the point of default, $\pi l^{0} / c^{0}$ and $l^{1} / c^{1}$, respectively.
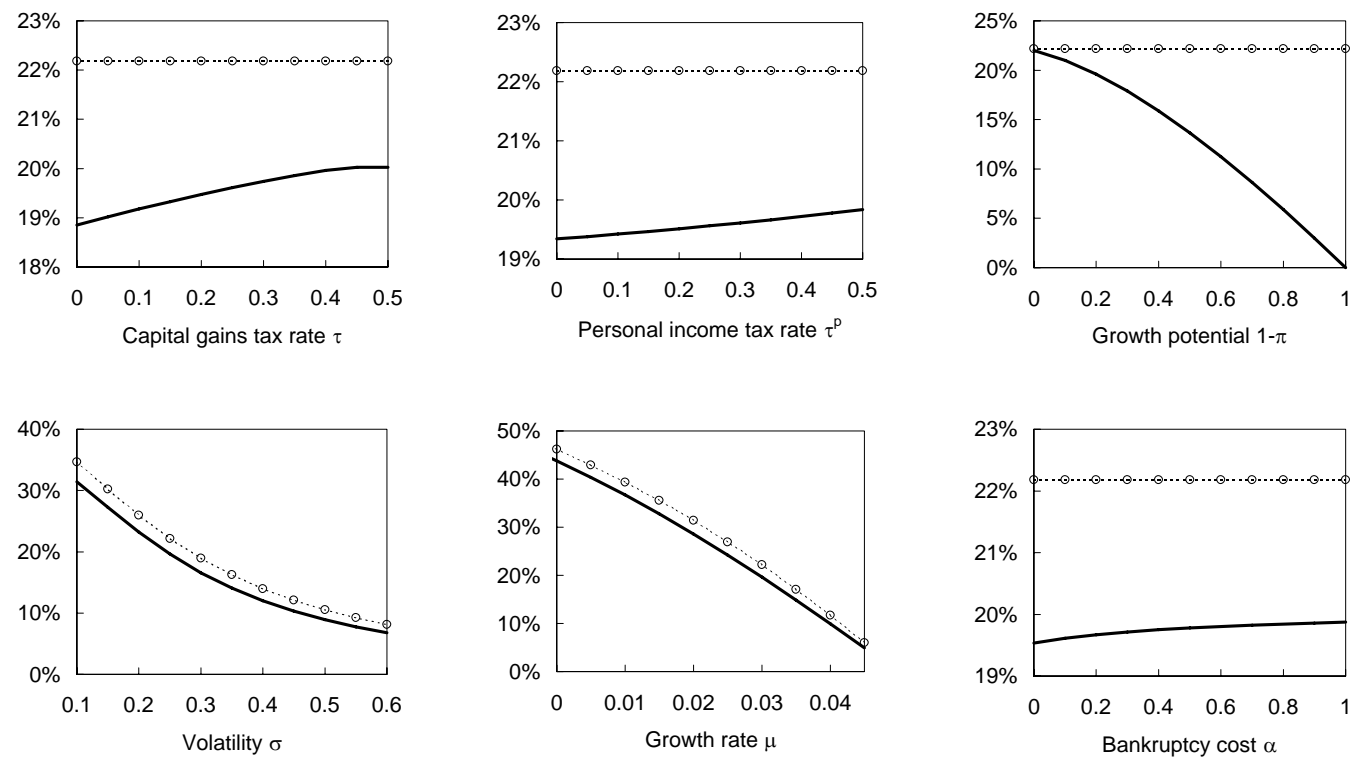
Table 1: PARAmeter VAlues.

\begin{tabular}{crl}
\hline Parameter & Value & \multicolumn{1}{c}{ Description } \\
\hline$r$ & $5 \%$ & After-tax risk-free rate \\
$\mu$ & $3 \%$ & Drift of operating income process \\
$\sigma$ & $25 \%$ & Volatility of operating income process \\
$\alpha$ & $25 \%$ & Default cost \\
$\tau$ & $25 \%$ & Capital gains tax rate \\
$\tau^{p}, \tau^{d}$ & $30 \%$ & Ordinary income tax rate on interest or dividends \\
$\tau^{c}$ & $20 \%$ & Effective corporate income tax rate \\
$\pi$ & $80 \%$ & Growth potential of the firm \\
\hline
\end{tabular}

Table 2: Investment Policy.

Table 2 reports comparative statics on the selected investment threshold contingent on the past performance of the firm. The first panel reports the investment trigger in terms of the state variable, and the second panel in terms of the threshold market-to-book ratio. Across columns the ratio of the owner's tax basis relative to the stock price at the investment date varies from 0 to 1 . The last column allows for a comparison of the investment triggers to the case when the tax rate on capital gains is nil.

\begin{tabular}{|c|c|c|c|c|c|}
\hline & \multicolumn{3}{|c|}{ Basis-price ratio } & \multirow{2}{*}{$\begin{array}{c}\text { Variation } \\
(0-1) / 1\end{array}$} & \multirow{2}{*}{$\begin{array}{c}\text { Benchmark } \\
\tau=0 \%\end{array}$} \\
\hline & 0 & 0.5 & 1 & & \\
\hline \multicolumn{6}{|c|}{ PANEL A: Investment threshold $[u(m) / I$ in $\%]$} \\
\hline Base & 58.4 & 32.0 & 27.9 & $109 \%$ & 55.2 \\
\hline$\tau=15 \%$ & 56.6 & 39.5 & 36.0 & $57 \%$ & 55.2 \\
\hline$\tau=35 \%$ & 61.0 & 26.0 & 21.9 & $178 \%$ & 55.2 \\
\hline$\tau=45 \%$ & 63.9 & 21.5 & 17.4 & $268 \%$ & 55.2 \\
\hline$\mu=2 \%$ & 62.0 & 40.2 & 36.5 & $70 \%$ & 59.5 \\
\hline$\mu=4 \%$ & 55.1 & 20.5 & 16.9 & $227 \%$ & 51.4 \\
\hline$\sigma=15 \%$ & 40.2 & 24.4 & 19.1 & $110 \%$ & 35.5 \\
\hline$\sigma=50 \%$ & 119.7 & 64.6 & 60.5 & $98 \%$ & 132.7 \\
\hline$\tau^{c}=15 \%$ & 62.2 & 34.5 & 29.9 & $108 \%$ & 58.8 \\
\hline$\tau^{c}=25 \%$ & 54.0 & 29.9 & 26.5 & $104 \%$ & 51.8 \\
\hline$\alpha=10 \%$ & 56.5 & 29.1 & 25.4 & $123 \%$ & 51.7 \\
\hline$\alpha=50 \%$ & 60.4 & 35.5 & 31.3 & $93 \%$ & 59.3 \\
\hline$\pi=50 \%$ & 25.4 & 19.2 & 17.8 & $42 \%$ & 27.2 \\
\hline$\pi=100 \%$ & 322.8 & 56.1 & 45.2 & $615 \%$ & 158.5 \\
\hline \multicolumn{6}{|c|}{ PANEL B: Market-to-book equity at the investment date $\left[E^{1} /\left(\frac{\pi}{1-\pi} I\right)\right]$} \\
\hline Base & 2.6 & 1.1 & 0.9 & $203 \%$ & 1.6 \\
\hline$\tau=15 \%$ & 2.1 & 1.3 & 1.1 & $92 \%$ & 1.6 \\
\hline$\tau=35 \%$ & 3.5 & 0.9 & 0.7 & $410 \%$ & 1.6 \\
\hline$\tau=45 \%$ & 5.4 & 0.8 & 0.5 & $885 \%$ & 1.6 \\
\hline$\mu=2 \%$ & 1.9 & 0.9 & 0.8 & $140 \%$ & 1.2 \\
\hline$\mu=4 \%$ & 4.9 & 1.4 & 1.0 & $387 \%$ & 3.0 \\
\hline$\sigma=15 \%$ & 1.4 & 0.6 & 0.4 & $238 \%$ & 0.8 \\
\hline$\sigma=50 \%$ & 6.4 & 2.9 & 2.6 & $145 \%$ & 4.8 \\
\hline$\tau^{c}=15 \%$ & 3.7 & 1.4 & 1.1 & $233 \%$ & 2.1 \\
\hline$\tau^{c}=25 \%$ & 2.0 & 0.9 & 0.7 & $179 \%$ & 1.3 \\
\hline$\alpha=10 \%$ & 2.2 & 0.8 & 0.6 & $261 \%$ & 1.2 \\
\hline$\alpha=50 \%$ & 3.1 & 1.5 & 1.2 & $155 \%$ & 2.2 \\
\hline$\pi=50 \%$ & 4.5 & 2.6 & 2.2 & $101 \%$ & 3.2 \\
\hline$\pi=100 \%$ & 0.6 & 0.1 & 0.1 & $955 \%$ & 0.2 \\
\hline
\end{tabular}




\section{Table 3: Financial Policy.}

Table 3 reports comparative statics results on the ex-post optimal capital structure of the firm. The first panel reports the target leverage ratio after the second round of financing. The second panel reports the credit spread at the target leverage ratio. Across the different columns, the ratio of the owner's tax basis relative to the stock price at the refinancing date varies from 0 to 1 . The last column allows for a comparison of the leverage levels to the case when the tax rate on capital gains is nil.

\begin{tabular}{|c|c|c|c|c|c|}
\hline & \multicolumn{3}{|c|}{ Basis-price ratio } & \multirow{2}{*}{$\begin{array}{c}\text { Variation } \\
(0-1) / 1\end{array}$} & \multirow{2}{*}{$\begin{array}{c}\text { Benchmark } \\
\tau=0 \%\end{array}$} \\
\hline & 0 & 0.5 & 1 & & \\
\hline \multicolumn{6}{|c|}{ PANEL A: Target leverage [in \%] } \\
\hline Base & 47.6 & 60.5 & 64.3 & $-26 \%$ & 61.2 \\
\hline$\tau=15 \%$ & 54.6 & 60.8 & 62.9 & $-13 \%$ & 61.2 \\
\hline$\tau=35 \%$ & 35.3 & 60.3 & 65.9 & $-46 \%$ & 61.2 \\
\hline$\tau=45 \%$ & 4.4 & 59.6 & 67.8 & $-94 \%$ & 61.2 \\
\hline$\mu=2 \%$ & 46.9 & 59.5 & 62.9 & $-25 \%$ & 59.9 \\
\hline$\mu=4 \%$ & 48.2 & 61.6 & 65.7 & $-27 \%$ & 62.5 \\
\hline$\sigma=15 \%$ & 58.6 & 69.9 & 74.6 & $-22 \%$ & 71.4 \\
\hline$\sigma=50 \%$ & 41.2 & 50.6 & 52.6 & $-22 \%$ & 50.6 \\
\hline$\tau^{c}=15 \%$ & 33.0 & 53.5 & 58.9 & $-44 \%$ & 55.1 \\
\hline$\tau^{c}=25 \%$ & 56.4 & 65.7 & 68.4 & $-17 \%$ & 65.8 \\
\hline$\alpha=10 \%$ & 54.5 & 68.6 & 72.3 & $-25 \%$ & 70.4 \\
\hline$\alpha=50 \%$ & 39.9 & 51.4 & 55.0 & $-27 \%$ & 50.4 \\
\hline$\pi=50 \%$ & 49.0 & 60.8 & 64.3 & $-24 \%$ & 61.2 \\
\hline$\pi=100 \%$ & 46.6 & 60.4 & 64.3 & $-28 \%$ & 61.2 \\
\hline \multicolumn{6}{|c|}{ PANEL B: Credit spread at target leverage [in bp] } \\
\hline Base & 58.4 & 103.2 & 120.9 & $-52 \%$ & 168.8 \\
\hline$\tau=15 \%$ & 100.5 & 128.7 & 139.9 & $-28 \%$ & 168.8 \\
\hline$\tau=35 \%$ & 21.3 & 79.1 & 102.4 & $-79 \%$ & 168.8 \\
\hline$\tau=45 \%$ & 0.1 & 55.5 & 84.3 & $-99 \%$ & 168.8 \\
\hline$\mu=2 \%$ & 73.5 & 122.4 & 140.0 & $-48 \%$ & 195.2 \\
\hline$\mu=4 \%$ & 45.8 & 86.6 & 104.4 & $-56 \%$ & 145.8 \\
\hline$\sigma=15 \%$ & 11.7 & 29.2 & 42.2 & $-72 \%$ & 58.6 \\
\hline$\sigma=50 \%$ & 382.5 & 479.0 & 501.6 & $-24 \%$ & 688.1 \\
\hline$\tau^{c}=15 \%$ & 28.6 & 77.9 & 97.5 & $-71 \%$ & 137.3 \\
\hline$\tau^{c}=25 \%$ & 84.7 & 126.6 & 142.4 & $-41 \%$ & 197.3 \\
\hline$\alpha=10 \%$ & 68.2 & 122.0 & 141.8 & $-52 \%$ & 200.2 \\
\hline$\alpha=50 \%$ & 49.6 & 87.0 & 102.5 & $-52 \%$ & 140.4 \\
\hline$\pi=50 \%$ & 62.5 & 104.6 & 120.9 & $-48 \%$ & 168.8 \\
\hline$\pi=100 \%$ & 55.8 & 102.6 & 120.9 & $-54 \%$ & 168.8 \\
\hline
\end{tabular}




\section{Table 4: Value Improvement Associated with State-Contingent Policies.}

Table 4 reports comparative statics results on the impact of state-contingent policies on the wealth of incumbents. The value creation is measured in terms of the increase in private valuations following a switch from market value maximizing policy choices to path-dependent private value maximizing policy choices. Across the different columns, the firm's past performance varies from worst $\left(m=l^{0}\right)$ to best $(m=\bar{m})$. Zero corresponds to the worst performance and a zero basis-price ratio. One corresponds to the best performance (no past drop in operating performance below $u(m)$ ) and a basis-price ratio of one.

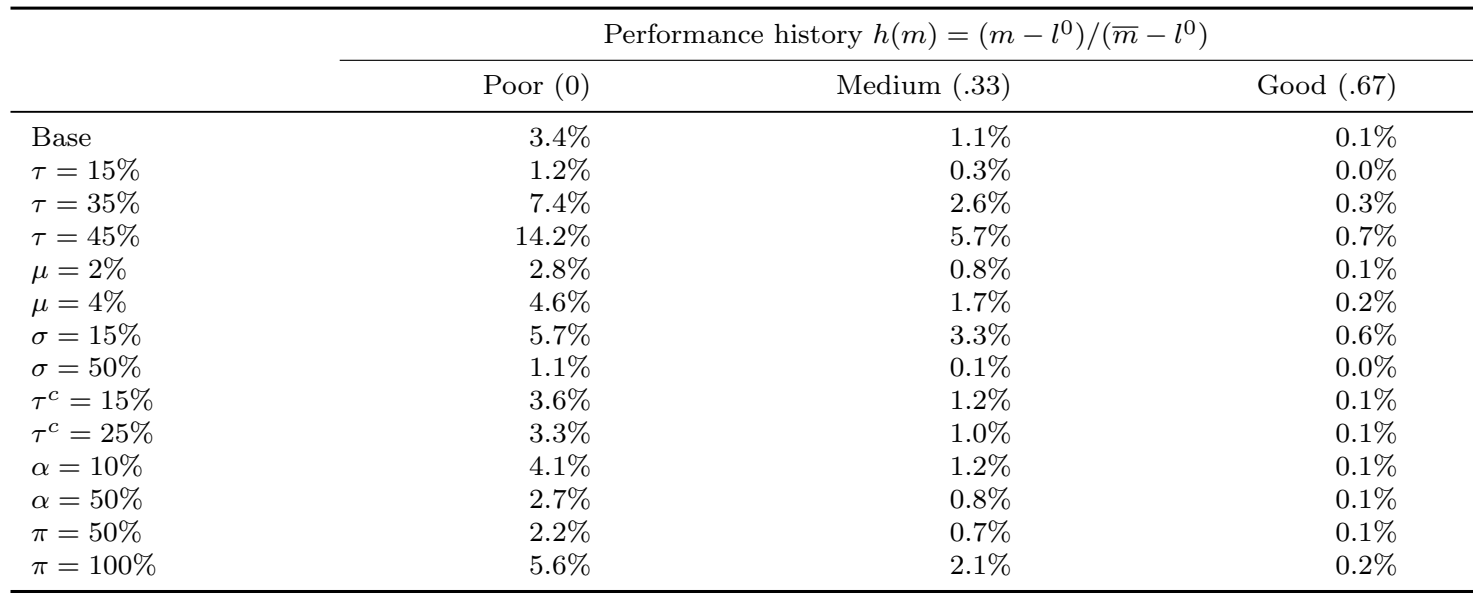

Table 5: Managerial Discretion and State-Contingent Policies.

Table 5 reports comparative statics results on the change in the selected investment threshold, target capital structure, and improvement in private values associated with policy choices that reflect the tax basis of the manager. In this table, the basis-price ratio for the manager's stock is set to $25 \%\left(B P_{u}=0.25\right)$.

\begin{tabular}{lrrc}
\hline & $\Delta$ Investment & $\Delta$ Leverage & $\Delta$ Value \\
\hline Base & $45.1 \%$ & $-13.9 \%$ & $1.4 \%$ \\
$\tau=15 \%$ & $26.2 \%$ & $-7.5 \%$ & $0.4 \%$ \\
$\tau=35 \%$ & $66.7 \%$ & $-22.1 \%$ & $3.2 \%$ \\
$\tau=45 \%$ & $96.8 \%$ & $-34.1 \%$ & $6.7 \%$ \\
$\mu=2 \%$ & $30.4 \%$ & $-13.3 \%$ & $1.0 \%$ \\
$\mu=4 \%$ & $73.6 \%$ & $-14.3 \%$ & $2.2 \%$ \\
$\sigma=15 \%$ & $72.2 \%$ & $-14.0 \%$ & $3.8 \%$ \\
$\sigma=50 \%$ & $22.8 \%$ & $-9.6 \%$ & $0.2 \%$ \\
$\tau^{c}=15 \%$ & $49.0 \%$ & $-22.5 \%$ & $1.6 \%$ \\
$\tau^{c}=25 \%$ & $41.4 \%$ & $-9.4 \%$ & $1.3 \%$ \\
$\alpha=10 \%$ & $46.4 \%$ & $-12.4 \%$ & $1.6 \%$ \\
$\alpha=50 \%$ & $41.2 \%$ & $-15.1 \%$ & $1.1 \%$ \\
$\pi=50 \%$ & $20.7 \%$ & $-12.6 \%$ & $0.8 \%$ \\
$\pi=100 \%$ & $105.5 \%$ & $-14.8 \%$ & $2.8 \%$ \\
\hline
\end{tabular}



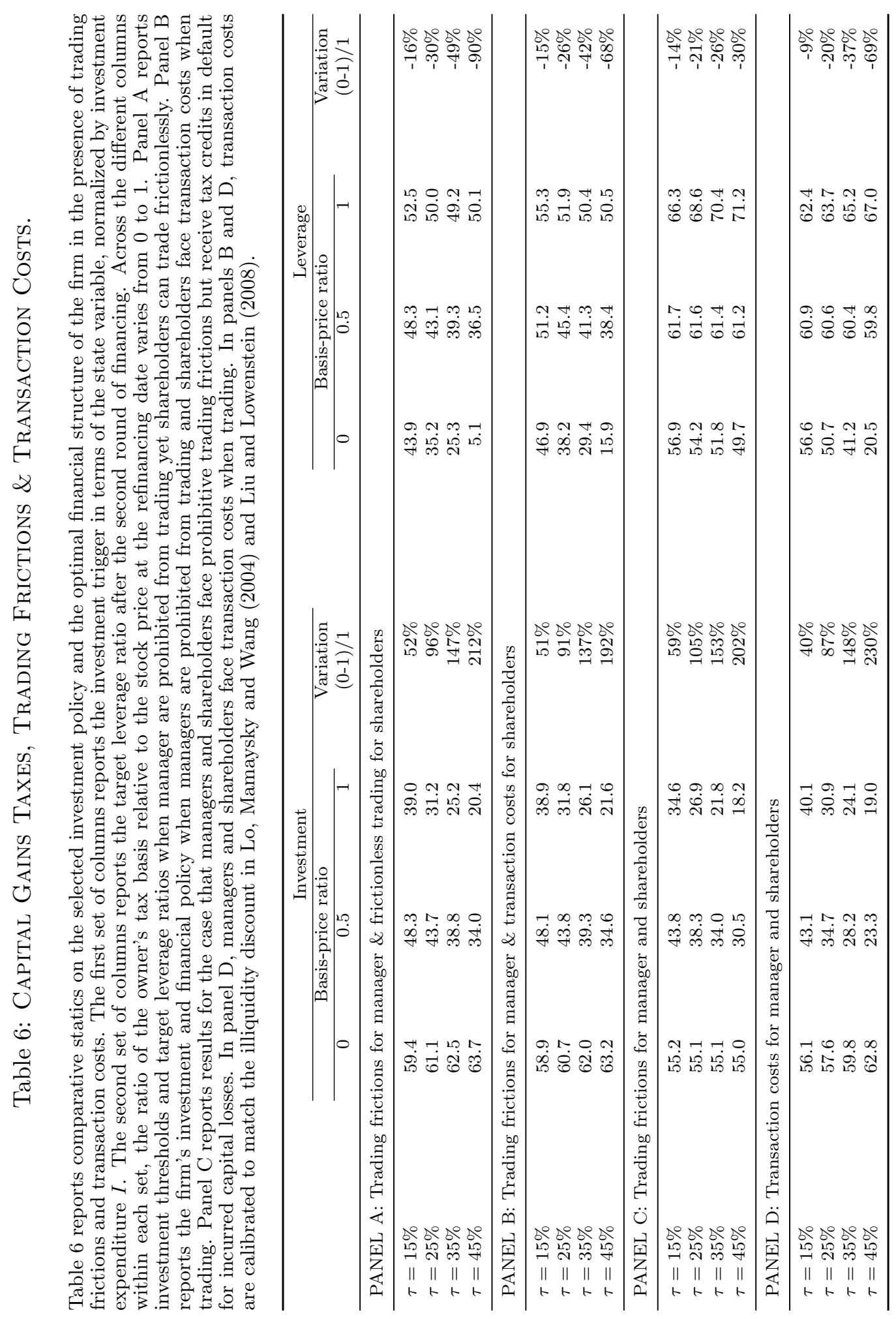


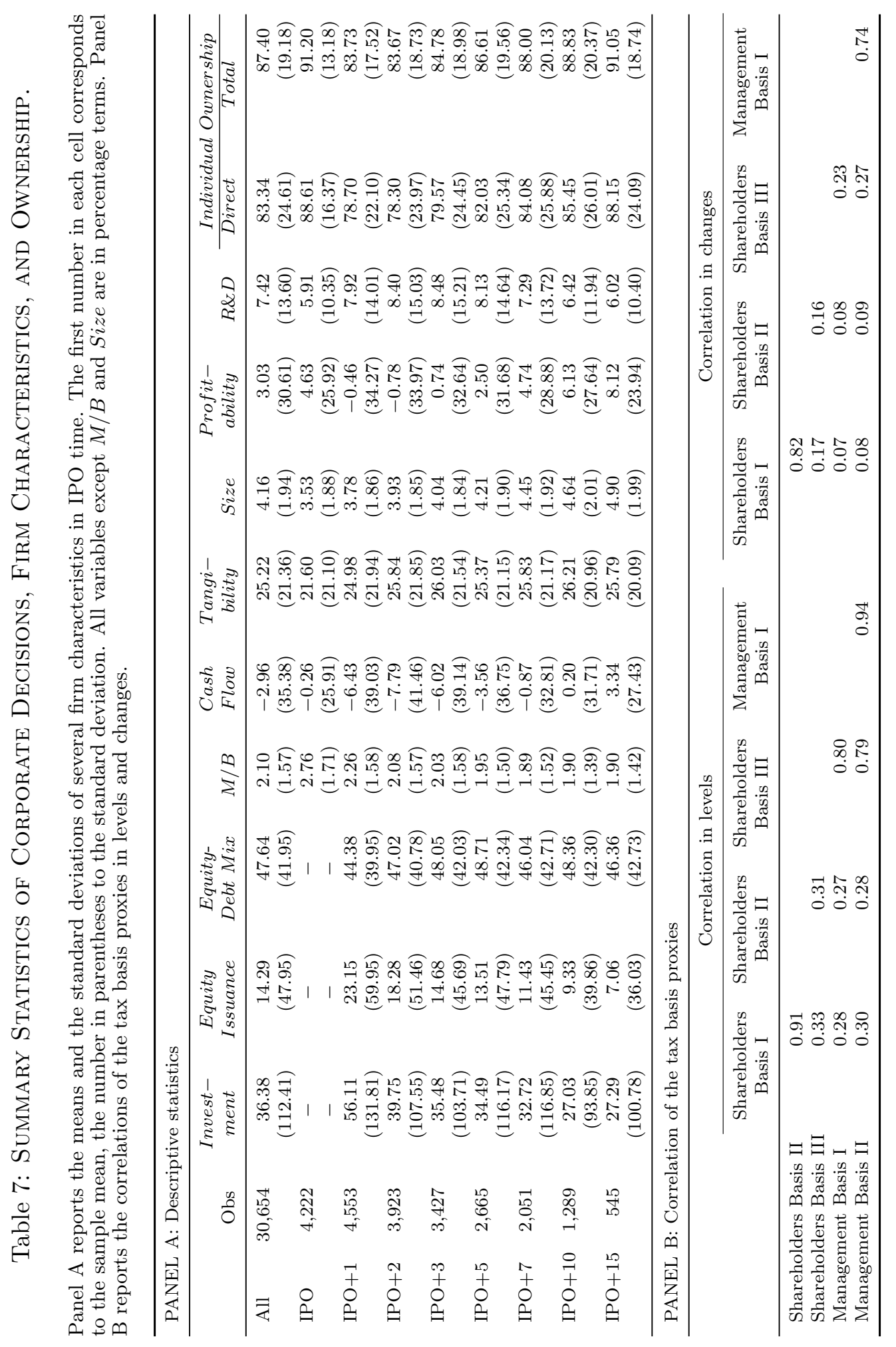


Table 8: Personal Tax Effects on Corporate Investment.

The table reports the coefficients from regressions of the form

$$
\begin{aligned}
& \text { Investment }_{t}=c_{0}+c_{1} \text { Shareholders }^{\prime} \text { Tax Basis } / O_{t-1}+c_{2} \text { Price } / O_{t-1}+c_{3} M / B_{t-1}+c_{4} \text { Cash Flow }_{t-1} \\
& +c_{5} \text { Asset Tangibility } \text { T }-1_{1}+c_{6} \text { Size }_{t-1}+c_{7} \text { Profitability }_{t-1}+c_{8} R \& D_{t-1}+c_{9} R D D_{t-1}+\epsilon_{t} .
\end{aligned}
$$

Standard errors are robust to clustering at the industry level defined by three-digit SIC codes and reported in parentheses. The dependent variable Investment $t_{t}$ is the total investment during the financial year $t-1$ through $t$ normalized by beginning of-the-year assets. All other variables are defined as described in the main text. The constant term and the coefficient on the dummy variable $R D D_{t-1}$ are not reported. In Panel A, all regressions are estimated with firm fixed effects. For robustness, Panel B reports the coefficients on the corresponding basis proxy for alternative specifications. In the last two specifications in Panel B, Tax Basis $/ O_{t-1}$ and Price $/ O_{t-1}$ are replaced by their ratio, Basis-Price Ratiot-1. Panel C reports estimation results from a logit analysis with firm fixed effects on the probability of large investment expenditures over the first five years following the IPO. The dependent variable takes a value of one if

\begin{tabular}{|c|c|c|c|}
\hline & $\begin{array}{l}\text { Shareholders } \\
\text { Basis Proxy I }\end{array}$ & $\begin{array}{l}\text { Shareholders } \\
\text { Basis Proxy II }\end{array}$ & $\begin{array}{l}\text { Shareholders } \\
\text { Basis Proxy III }\end{array}$ \\
\hline \multicolumn{4}{|c|}{ PANEL A: Regression analysis } \\
\hline Tax Basis $/ O_{t-1}$ & $\begin{array}{l}14.77 * * * \\
(3.23)\end{array}$ & $\begin{array}{l}14.98 * * * \\
(3.98)\end{array}$ & $\begin{array}{l}2.54 * * * \\
(0.44)\end{array}$ \\
\hline Price $/ O_{t-1}$ & $\begin{array}{l}0.10 \\
(0.28)\end{array}$ & $\begin{array}{l}0.12 \\
(0.28)\end{array}$ & $\begin{array}{l}-1.63 * * * \\
(0.37)\end{array}$ \\
\hline$M / B_{t-1}$ & $\begin{array}{l}1.55 * \\
(0.81)\end{array}$ & $\begin{array}{l}1.78 * * \\
(0.81)\end{array}$ & $\begin{array}{l}2.25 * * * \\
(0.79)\end{array}$ \\
\hline Cash Flow fl-1 & $\begin{array}{c}-0.02 \\
(0.05)\end{array}$ & $\begin{array}{l}-0.01 \\
(0.05)\end{array}$ & $\begin{array}{c}-0.01 \\
(0.05)\end{array}$ \\
\hline Asset Tangibility $_{t-1}$ & $\begin{array}{l}-0.54 * * * \\
(0.17)\end{array}$ & $\begin{array}{l}-0.56 * * * \\
(0.17)\end{array}$ & $\begin{array}{c}-0.55 * * * \\
(0.17)\end{array}$ \\
\hline Size $_{t-1}$ & $\begin{array}{l}-17.12 * * * \\
(2.75)\end{array}$ & $\begin{array}{c}-17.31 * * * \\
(2.75)\end{array}$ & $\begin{array}{c}-18.73 * * * \\
(2.79)\end{array}$ \\
\hline Profitability $y_{-1}$ & $\begin{array}{c}0.18 * \\
(0.10)\end{array}$ & $\begin{array}{c}0.19 * \\
(0.10)\end{array}$ & $\begin{array}{l}0.21 * * \\
(0.10)\end{array}$ \\
\hline$R \& D_{t-1}$ & $\begin{array}{l}0.39 * * * \\
(0.10)\end{array}$ & $\begin{array}{l}0.38 * * * \\
(0.10)\end{array}$ & $\begin{array}{l}0.38 * * * \\
(0.10)\end{array}$ \\
\hline Observations & 25,779 & 25,779 & 25,779 \\
\hline \multicolumn{4}{|c|}{ PANEL B: Robustness - alternative specifications (coef. $c_{1}$ on basis proxy reported) } \\
\hline $\begin{array}{l}\text { Tax Basis } / O_{t-1} \\
\text { [random effect] }\end{array}$ & $\begin{array}{l}12.72 * * * \\
(3.02)\end{array}$ & $\begin{array}{l}13.79 * * * \\
(3.56)\end{array}$ & $\begin{array}{l}2.67 * * * \\
(0.43)\end{array}$ \\
\hline $\begin{array}{l}\text { Tax Basis } / O_{t} \\
\quad[\text { fixed effect IV] }\end{array}$ & $\begin{array}{l}28.80 * * * \\
(3.56)\end{array}$ & $\begin{array}{l}23.36 * * * \\
(3.24)\end{array}$ & $\begin{array}{l}7.93 * * * \\
(1.45)\end{array}$ \\
\hline $\begin{array}{l}\text { Basis-Price Ratiot-1 } \\
\quad \text { [fixed effect] }\end{array}$ & $\begin{array}{l}10.41 * * * \\
(3.01)\end{array}$ & $\begin{array}{l}-0.25 \\
(0.75)\end{array}$ & $\begin{array}{r}4.01 * \\
(2.08)\end{array}$ \\
\hline \multicolumn{4}{|c|}{ PANEL C: Logit analysis of $\mathbb{P}\left(\right.$ Investment $_{t} \geq$ Industry Avg. $)$} \\
\hline $\begin{array}{l}\text { Tax Basis } / O_{t-1} \\
\text { [fixed effect] }\end{array}$ & $\begin{array}{l}2.17 * * * \\
(0.29)\end{array}$ & $\begin{array}{l}2.39 * * * \\
(0.40)\end{array}$ & $\begin{array}{c}-0.03 \\
(0.17)\end{array}$ \\
\hline $\begin{array}{l}\text { Tax Basis } / O_{t-1} \\
\text { [random effect] }\end{array}$ & $\begin{array}{l}1.42 * * * \\
(0.18)\end{array}$ & $\begin{array}{l}1.94 * * * \\
(0.24)\end{array}$ & $\begin{array}{c}-0.18 \\
(0.13)\end{array}$ \\
\hline
\end{tabular}
investment expenditures exceed industry average, and zero otherwise. 
Table 9: Individual Ownership \& Sensitivity of Corporate Investment to Personal TAXes.

For each subsample of firms defined by the portion of stock held by individual investors, the table reports the coefficients from regressions of the form

$$
\begin{aligned}
& \text { Investment }_{t}=c_{0}+c_{1} \text { Shareholders }^{\prime} \text { Tax Basis } / O_{t-1}+c_{2} \text { Price } / O_{t-1}+c_{3} M / B_{t-1}+c_{4} \text { Cash Flow }_{t-1} \\
& +c_{5} \text { Asset Tangibility }_{t-1}+c_{6} \text { Size }_{t-1}+c_{7} \text { Profitability }_{t-1}+c_{8} R \& D_{t-1}+c_{9} R D D_{t-1}+\epsilon_{t} .
\end{aligned}
$$

Standard errors are robust to clustering at the industry level defined by three-digit SIC codes and reported in parentheses. The dependent variable Investment $_{t}$ is the total investment during the financial year $t-1$ through $t$ normalized by beginning of-the-year assets. All other variables are defined as described in the main text. All regressions are estimated with firm fixed effects. The constant term and the coefficients on Asset Tangibility T $-1_{1}$, Size $e_{t-1}$, Profitability $t_{-1}, R \& D_{t-1}$, and the dummy variable $R D D_{t-1}$ are not reported. Panel A splits the sample of firms by the portion of stock held by individual investors directly or through mutual funds. Panel B splits the sample of firms by the portion of stock held directly by individual investors. In the second part of each panel we report the coefficients $c_{1}$ on Tax Basis $/ O_{t-1}$

\begin{tabular}{|c|c|c|c|c|}
\hline & \multicolumn{4}{|c|}{ Individual Ownership } \\
\hline & $0-100 \%$ & $\geq 80 \%$ & $50-80 \%$ & $<50 \%$ \\
\hline \multicolumn{5}{|c|}{ PANEL A: Total Individual Ownership } \\
\hline Tax Basis $/ O_{t-1}$ & $\begin{array}{l}14.81 * * * \\
(3.22)\end{array}$ & $\begin{array}{l}17.32 * * * \\
(5.26)\end{array}$ & $\begin{array}{l}4.45 * * * \\
(1.33)\end{array}$ & $\begin{array}{c}1.16 \\
(1.17)\end{array}$ \\
\hline Price $/ O_{t-1}$ & $\begin{array}{c}0.17 \\
(0.23)\end{array}$ & $\begin{array}{l}-1.87 * * * \\
(0.64)\end{array}$ & $\begin{array}{c}-0.21 \\
(0.15)\end{array}$ & $\begin{array}{c}-0.05 \\
(0.04)\end{array}$ \\
\hline$M / B_{t-1}$ & $\begin{array}{l}1.77 * * \\
(0.76)\end{array}$ & $\begin{array}{l}4.34 * * * \\
(1.29)\end{array}$ & $\begin{array}{l}0.71 * * * \\
(0.26)\end{array}$ & $\begin{array}{l}0.24 * * * \\
(0.08)\end{array}$ \\
\hline Cash Flow $_{t-1}$ & $\begin{array}{c}0.02 \\
(0.04)\end{array}$ & $\begin{array}{c}0.03 \\
(0.07)\end{array}$ & $\begin{array}{c}0.02 \\
(0.01)\end{array}$ & $\begin{array}{c}-0.01 \\
(0.02)\end{array}$ \\
\hline Observations & 23,994 & 12,768 & 8,058 & 3,168 \\
\hline \multicolumn{5}{|c|}{ Robustness check - alternative basis proxies (coef. $c_{1}$ on Tax Basis $/ O_{t-1}$ reported) } \\
\hline Basis Proxy II & $\begin{array}{l}12.46 * * * \\
(3.82)\end{array}$ & $\begin{array}{l}15.40 * * \\
(6.37)\end{array}$ & $\begin{array}{l}4.38 * * * \\
(1.66)\end{array}$ & $\begin{array}{c}0.82 \\
(1.26)\end{array}$ \\
\hline Basis Proxy III & $\begin{array}{l}1.87 * * * \\
(0.37)\end{array}$ & $\begin{array}{c}0.74 \\
(1.66)\end{array}$ & $\begin{array}{r}0.23 * \\
(0.12)\end{array}$ & $\begin{array}{c}0.03 \\
(0.06)\end{array}$ \\
\hline \multicolumn{5}{|c|}{ PANEL B: Direct Individual Ownership } \\
\hline Tax Basis $/ O_{t-1}$ & $\begin{array}{l}14.81 * * * \\
(3.22)\end{array}$ & $\begin{array}{l}22.47 * * * \\
(6.00)\end{array}$ & $\begin{array}{c}4.21 * * \\
(1.91)\end{array}$ & $\begin{array}{l}1.89 * * \\
(0.87)\end{array}$ \\
\hline Price $/ O_{t-1}$ & $\begin{array}{c}0.17 \\
(0.23)\end{array}$ & $\begin{array}{l}-2.50 * * * \\
(0.81)\end{array}$ & $\begin{array}{r}-0.36 * \\
(0.19)\end{array}$ & $\begin{array}{c}-0.04 \\
(0.04)\end{array}$ \\
\hline$M / B_{t-1}$ & $\begin{array}{l}1.77 * * \\
(0.76)\end{array}$ & $\begin{array}{l}4.75 * * * \\
(1.54)\end{array}$ & $\begin{array}{l}1.16 * * * \\
(0.34)\end{array}$ & $\begin{array}{l}0.21 * * \\
(0.08)\end{array}$ \\
\hline Cash Flow $_{t-1}$ & $\begin{array}{c}0.02 \\
(0.04)\end{array}$ & $\begin{array}{c}0.04 \\
(0.08)\end{array}$ & $\begin{array}{c}-0.01 \\
(0.01)\end{array}$ & $\begin{array}{c}0.00 \\
(0.01)\end{array}$ \\
\hline Observations & 23,994 & 10,313 & 8,041 & 5,640 \\
\hline \multicolumn{5}{|c|}{ Robustness check - alternative basis proxies (coef. $c_{1}$ on Tax Basis $/ O_{t-1}$ reported) } \\
\hline Basis Proxy II & $\begin{array}{l}12.46 * * * \\
(3.82)\end{array}$ & $\begin{array}{l}21.79 * * * \\
(7.54)\end{array}$ & $\begin{array}{c}4.34 * * \\
(2.20)\end{array}$ & $\begin{array}{l}2.26 * * \\
(1.06)\end{array}$ \\
\hline Basis Proxy III & $\begin{array}{l}1.87 * * * \\
(0.37)\end{array}$ & $\begin{array}{c}0.30 \\
(2.28)\end{array}$ & $\begin{array}{c}0.08 \\
(0.35)\end{array}$ & $\begin{array}{c}0.05 \\
(0.08)\end{array}$ \\
\hline
\end{tabular}
for alternative proxies for the tax basis. 


\section{Table 10: Personal Tax Effects on External Financing.}

The table reports the coefficients from regressions of the form

$$
\begin{gathered}
\text { Equity Issuance } \text { Is }_{t}=c_{0}+c_{1} \text { Shareholders' }^{\prime} \text { Tax Basis } / O_{t-1}+c_{2} \text { Price } / O_{t-1}+c_{3} M / B_{t-1}+c_{4} M / B_{t-1}^{e f w a} \\
+c_{5} C_{t-1}+c_{6} \text { Tangibility }_{t-1}+c_{7} \text { Size }_{t-1}+c_{8} \text { Profitability } \text { Pr-1 }_{t-1}+c_{9} R \& D_{t-1}+c_{10} R D D_{t-1}+\epsilon_{t}
\end{gathered}
$$

Standard errors are robust to clustering at the industry level defined by three-digit SIC codes and reported in parentheses. The dependent variable Equity Issuance is $_{\text {s }}$ the change in book equity net of the change in retained earnings during the financial year $t-1$ through $t$ divided by year-end assets in the IPO year. Equity-Debt Mix $x_{t}$ is the portion of external funds raised in the form of equity during the financial year and takes values between zero and one. All other variables are defined as described in the main text. The constant term and the coefficient on the dummy variable $R D D_{t-1}$ are not reported. In Panel A, all regressions are estimated with firm fixed effects. For robustness, Panel B reports the coefficients on the corresponding basis proxy for alternative specifications. In the last two specifications in Panel B, Tax Basis $/ O_{t-1}$ and Price $/ O_{t-1}$ are replaced by their ratio, Basis-Price Ratiot-1. Panel C reports

\begin{tabular}{|c|c|c|c|}
\hline & $\begin{array}{l}\text { Shareholders } \\
\text { Basis Proxy I }\end{array}$ & $\begin{array}{l}\text { Shareholders } \\
\text { Basis Proxy II }\end{array}$ & $\begin{array}{l}\text { Shareholders } \\
\text { Basis Proxy III }\end{array}$ \\
\hline \multicolumn{4}{|c|}{ PANEL A: Equity Issuancet } \\
\hline Tax Basis/Ot-1 & $\begin{array}{l}-8.57 * * * \\
(1.83)\end{array}$ & $\begin{array}{l}-8.32 * * * \\
(1.88)\end{array}$ & $\begin{array}{c}-0.83 * * \\
(0.39)\end{array}$ \\
\hline Price $/ O_{t-1}$ & $\begin{array}{c}-0.50 * * \\
(0.20)\end{array}$ & $\begin{array}{l}-0.51 * * \\
(0.20)\end{array}$ & $\begin{array}{c}0.04 \\
(0.28)\end{array}$ \\
\hline$M / B_{t-1}$ & $\begin{array}{l}8.80 * * * \\
(1.45)\end{array}$ & $\begin{array}{l}8.68 * * * \\
(1.44)\end{array}$ & $\begin{array}{l}8.54 * * * \\
(1.45)\end{array}$ \\
\hline$M / B_{t-1}^{e f w a}$ & $\begin{array}{l}1.48 \\
(1.62)\end{array}$ & $\begin{array}{l}1.44 \\
(1.63)\end{array}$ & $\begin{array}{c}1.27 \\
(1.66)\end{array}$ \\
\hline Cash Flow Fl $_{1}$ & $\begin{array}{l}0.18 * * * \\
(0.06)\end{array}$ & $\begin{array}{l}0.18 * * * \\
(0.06)\end{array}$ & $\begin{array}{l}0.17 * * * \\
(0.06)\end{array}$ \\
\hline Asset Tangibility $y_{-1}$ & $\begin{array}{l}0.24 * * * \\
(0.04)\end{array}$ & $\begin{array}{l}0.25 * * * \\
(0.04)\end{array}$ & $\begin{array}{l}0.24 * * * \\
(0.04)\end{array}$ \\
\hline Sizet $-1_{1}$ & $\begin{array}{l}-4.35 * * * \\
(0.89)\end{array}$ & $\begin{array}{l}-4.23 * * * \\
(0.91)\end{array}$ & $\begin{array}{l}-3.55 * * * \\
(0.96)\end{array}$ \\
\hline Profitability $_{t-1}$ & $\begin{array}{l}-0.24 * * * \\
(0.08)\end{array}$ & $\begin{array}{l}-0.24 * * * \\
(0.08)\end{array}$ & $\begin{array}{l}-0.25 * * * \\
(0.08)\end{array}$ \\
\hline$R \& D_{t-1}$ & $\begin{array}{l}1.11 * * * \\
(0.23)\end{array}$ & $\begin{array}{l}1.12 * * * \\
(0.23)\end{array}$ & $\begin{array}{l}1.12 * * * \\
(0.22)\end{array}$ \\
\hline Observations & 25,502 & 25,502 & 25,502 \\
\hline \multicolumn{4}{|c|}{ PANEL B: Robustness - alternative specifications (coef. $c_{1}$ on basis proxy reported) } \\
\hline $\begin{array}{l}\text { Tax Basis } / O_{t-1} \\
\text { [random effect] }\end{array}$ & $\begin{array}{c}1.37 \\
(0.90)\end{array}$ & $\begin{array}{c}1.13 \\
(1.00)\end{array}$ & $\begin{array}{c}-0.94 * * * \\
(0.34)\end{array}$ \\
\hline $\begin{array}{l}\text { Tax Basis } / O_{t} \\
\quad[\text { fixed effect IV] }\end{array}$ & $\begin{array}{l}-19.25 * * * \\
(2.33)\end{array}$ & $\begin{array}{l}-15.47 * * * \\
(2.11)\end{array}$ & $\begin{array}{l}-2.76 * * * \\
(0.92)\end{array}$ \\
\hline $\begin{array}{l}\text { Basis-Price } \text { Ratio }_{t-1} \\
\quad \text { [fixed effect] }\end{array}$ & $\begin{array}{r}-1.23 \\
(1.80)\end{array}$ & $\begin{array}{c}-0.12 \\
(0.57)\end{array}$ & $\begin{array}{l}-8.69 * * * \\
(1.00)\end{array}$ \\
\hline \multicolumn{4}{|c|}{ PANEL C: Equity-Debt Mix (coef. $c_{1}$ on basis proxy reported) } \\
\hline $\begin{array}{l}\text { Tax Basis } / O_{t-1} \\
\text { [fixed effect] }\end{array}$ & $\begin{array}{c}-13.41 * * * \\
(2.87)\end{array}$ & $\begin{array}{c}-10.77 * * * \\
(2.87)\end{array}$ & $\begin{array}{c}-1.16 * * \\
(0.51)\end{array}$ \\
\hline $\begin{array}{l}\text { Tax Basis } / O_{t-1} \\
\text { [random effect] }\end{array}$ & $\begin{array}{l}-8.82 * * * \\
(1.19)\end{array}$ & $\begin{array}{l}-8.92 * * * \\
(1.22)\end{array}$ & $\begin{array}{c}-0.47 \\
(0.46)\end{array}$ \\
\hline $\begin{array}{l}\text { Tax Basis } / O_{t} \\
\quad[\text { fixed effect IV] }\end{array}$ & $\begin{array}{l}-25.78 * * * \\
(3.11)\end{array}$ & $\begin{array}{c}-16.61 * * * \\
(2.83)\end{array}$ & $\begin{array}{c}-3.72 * * * \\
(1.20)\end{array}$ \\
\hline
\end{tabular}
estimation results for the effect of the tax basis on the Equity-Debt Mix $x_{t}$ as dependent variable. 
Table 11: Individual Ownership \& Sensitivity of External Financing to PerSONAL TAXES.

For each subsample of firms defined by the portion of stock held by individual investors, the table reports the coefficients from regressions of the form

$$
\begin{aligned}
& \text { Equity Issuance }{ }_{t}=c_{0}+c_{1} \text { Shareholders }^{\prime} \text { Tax Basis } / O_{t-1}+c_{2} \text { Price } / O_{t-1}+c_{3} M / B_{t-1}+c_{4} M / B_{t-1}^{\text {efwa }} \\
& +c_{5} \text { CF }_{t-1}+c_{6} \text { Tangibility }_{t-1}+c_{7} \text { Size }_{t-1}+c_{8} \text { Profitability } \text { Pr-1 }_{t-1}+c_{9} R \& D_{t-1}+c_{10} R D D_{t-1}+\epsilon_{t} .
\end{aligned}
$$

Standard errors are robust to clustering at the industry level defined by three-digit SIC codes and reported in parentheses. The dependent variable Equity Issuance is ise change in book equity net of the change in retained earnings during the financial year $t-1$ through $t$ normalized by beginning of-theyear assets. All other variables are defined as described in the main text. All regressions are estimated with firm fixed effects. The constant term and the coefficients on $M / B_{t-1}, M / B_{t-1}^{\text {efwa }}$, Cash Flow Cl-1 $_{\text {, }}$, Asset Tangibility $_{t-1}$, Size $_{t-1}$, Profitability $t_{-1}, R \& D_{t-1}$, and the dummy variable $R D D_{t-1}$ are not reported. Panel A splits the sample of firms by the portion of stock held by individual investors directly or through mutual funds. Panel B splits the sample of firms by the portion of stock held directly by individual investors. The second part in each panel reports the coefficients on Tax Basis $/ O_{t-1}$ for the

\begin{tabular}{|c|c|c|c|c|}
\hline & \multicolumn{4}{|c|}{ Individual Ownership } \\
\hline & $0-100 \%$ & $\geq 80 \%$ & $50-80 \%$ & $<50 \%$ \\
\hline \multicolumn{5}{|c|}{ PANEL A: Total individual ownership } \\
\hline Tax Basis $/ O_{t-1}$ & $\begin{array}{l}-9.06 * * * \\
(1.82)\end{array}$ & $\begin{array}{c}-12.09 * * * \\
(1.83)\end{array}$ & $\begin{array}{c}-5.42 \\
(3.40)\end{array}$ & $\begin{array}{c}-6.56 * \\
(3.83)\end{array}$ \\
\hline Price $/ O_{t-1}$ & $\begin{array}{l}-0.54 * * \\
(0.21)\end{array}$ & $\begin{array}{c}-1.03 * * * \\
(0.30)\end{array}$ & $\begin{array}{c}-0.65 * * \\
(0.30)\end{array}$ & $\begin{array}{c}-0.28 * \\
(0.15)\end{array}$ \\
\hline$M / B_{t-1}$ & $\begin{array}{l}8.87 * * * \\
(1.49)\end{array}$ & $\begin{array}{l}9.86 * * * \\
(1.28)\end{array}$ & $\begin{array}{l}8.14 * * * \\
(1.99)\end{array}$ & $\begin{array}{l}7.25 * * * \\
(1.50)\end{array}$ \\
\hline Cash Flow f $_{-1}$ & $\begin{array}{l}0.19 * * * \\
(0.06)\end{array}$ & $\begin{array}{l}0.16 * * * \\
(0.04)\end{array}$ & $\begin{array}{c}0.21 * \\
(0.12)\end{array}$ & $\begin{array}{l}0.48 * * * \\
(0.12)\end{array}$ \\
\hline Observations & 23,940 & 12,704 & 8,065 & 3,171 \\
\hline \multicolumn{5}{|c|}{ Robustness check - alternative basis proxies (coef. $c_{1}$ on Tax Basis $/ O_{t-1}$ reported) } \\
\hline Basis Proxy II & $\begin{array}{l}-8.73 * * * \\
(2.01)\end{array}$ & $\begin{array}{c}-10.51 * * * \\
(2.61)\end{array}$ & $\begin{array}{l}-6.11 \\
(4.65)\end{array}$ & $\begin{array}{c}-8.17 * \\
(4.62)\end{array}$ \\
\hline Basis Proxy III & $\begin{array}{c}-0.68 \\
(0.43)\end{array}$ & $\begin{array}{l}-3.94 * * * \\
(1.04)\end{array}$ & $\begin{array}{c}-0.21 \\
(0.45)\end{array}$ & $\begin{array}{r}0.88 * \\
(0.47)\end{array}$ \\
\hline \multicolumn{5}{|c|}{ PANEL B: Direct individual ownership } \\
\hline Tax Basis $/ O_{t-1}$ & $\begin{array}{l}-9.06 * * * \\
(1.82)\end{array}$ & $\begin{array}{c}-12.17 * * * \\
(2.11)\end{array}$ & $\begin{array}{c}-10.62 * * * \\
(3.67)\end{array}$ & $\begin{array}{l}-2.99 \\
(2.45)\end{array}$ \\
\hline Price $/ O_{t-1}$ & $\begin{array}{c}-0.54 * * \\
(0.21)\end{array}$ & $\begin{array}{c}-0.99 * * \\
(0.41)\end{array}$ & $\begin{array}{c}-1.01 * * * \\
(0.31)\end{array}$ & $\begin{array}{c}-0.42 \\
(0.27)\end{array}$ \\
\hline$M / B_{t-1}$ & $\begin{array}{l}8.87 * * * \\
(1.49)\end{array}$ & $\begin{array}{l}9.44 * * * \\
(1.16)\end{array}$ & $\begin{array}{l}7.93 * * * \\
(1.52)\end{array}$ & $\begin{array}{l}8.57 * * * \\
(2.28)\end{array}$ \\
\hline Cash Flow $_{t-1}$ & $\begin{array}{l}0.19 * * * \\
(0.06)\end{array}$ & $\begin{array}{l}0.18 * * * \\
(0.05)\end{array}$ & $\begin{array}{c}0.17 \\
(0.14)\end{array}$ & $\begin{array}{l}0.34 * * * \\
(0.06)\end{array}$ \\
\hline Observations & 23,940 & 10,231 & 8,058 & 5,651 \\
\hline \multicolumn{5}{|c|}{ Robustness check - alternative basis proxies (coef. $c_{1}$ on Tax Basis $/ O_{t-1}$ reported) } \\
\hline Basis Proxy II & $\begin{array}{l}-8.73 * * * \\
(2.01)\end{array}$ & $\begin{array}{c}-11.29 * * * \\
(3.25)\end{array}$ & $\begin{array}{c}-11.21 * * \\
(4.63)\end{array}$ & $\begin{array}{c}-3.65 \\
(3.27)\end{array}$ \\
\hline Basis Proxy III & $\begin{array}{c}-0.68 \\
(0.43)\end{array}$ & $\begin{array}{l}-4.18 * * * \\
(1.23)\end{array}$ & $\begin{array}{c}-0.84 \\
(0.55)\end{array}$ & $\begin{array}{c}0.35 \\
(0.44)\end{array}$ \\
\hline
\end{tabular}
alternative definitions of the investors' tax basis. 


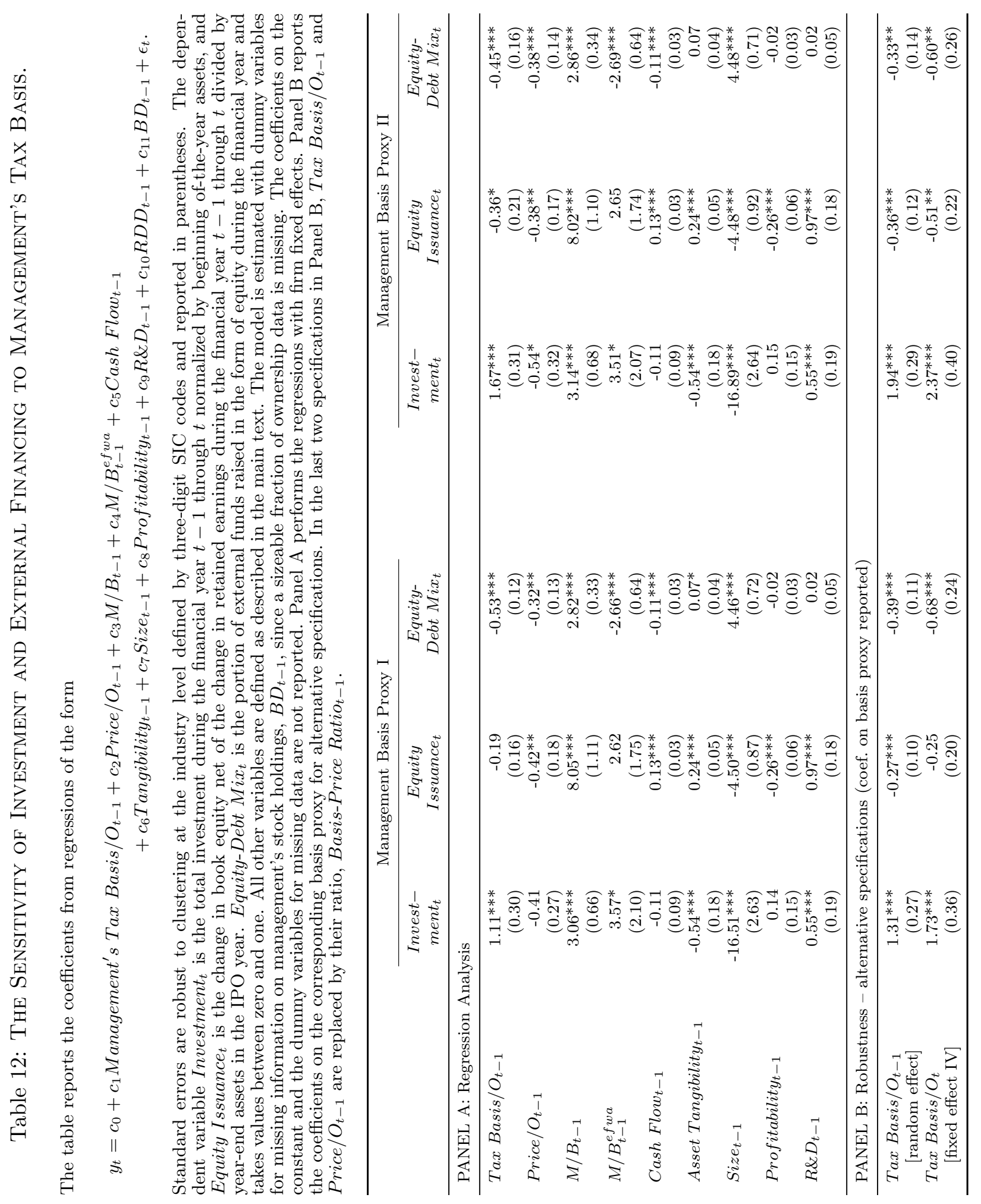

